\title{
LA ESTAFA TRIANGULAR EN EL DERECHO PENAL CHILENO, EN ESPECIAL LA ESTAFA PROCESAL
}

\author{
Héctor Hernández Basualto*
}

\begin{abstract}
RESUMEN
El artículo aborda las dificultades interpretativas de la llamada estafa triangular, esto es, de aquélla en que el sujeto engañado que realiza la disposición perjudicial es uno distinto del titular del patrimonio afectado. Específicamente, analiza el tipo de relación que debe existir entre engañado y patrimonio perjudicado para aceptar que aquél realiza la disposición típica exigida por la estafa. Al efecto se sostiene que no basta un simple poder fáctico de disposición, sino que se requiere una facultad para disponer. Por último se analiza el caso particular de la estafa procesal, con especial preocupación por la posibilidad conceptual de engaño y error en un contexto altamente formalizado. Para la exigencia de error se asume una interpretación que supone la normativización del concepto, enfatizando su función por sobre el becho psíquico al que tradicionalmente ha estado asociado.
\end{abstract}

ESTAFA TRIANGULAR - ESTAFA PROCESAL - ERROR

Triangular fraud in Chilean criminal law, especially procedural fraud

\begin{abstract}
This article deals with the interpretative difficulties of the so called triangular fraud, which is a fraud where the deceived subject that carries out a detrimental disposition is one different than the holder of the affected patrimony. Specifically, it analyzes the type of relationship that there should be between the deceived and the affected patrimony to accept that the first carries out the typical disposition demanded by the fraud. It is stated that one simple de facto power is not enough, but a faculty to order is required. Finally, the particular case of procedural frand is analyzed, with special concern on the conceptual possibility of deceit and error in a bighly formal context. With regard to the error demand, the paper assumes an interpretation that makes the concept normative, stressing its function over the psychic fact with which it has been traditionally associated.
\end{abstract}

TRIANGULAR FRAUD - PROCEDURAL FRAUD - ERROR

* Abogado, legum magister y Doctor en Derecho, Profesor de Derecho Penal en la Universidad Diego Portales, Santiago de Chile. Este trabajo se inscribe en el proyecto de investigación Fondecyt 1085159, "Cuestiones fundamentales de la dogmática de la estafa en el derecho penal chileno", ejecutado por el autor en la Universidad Diego Portales en calidad de investigador responsable. Hector.hernandez@udp.cl

Artículo enviado el 30 de marzo de 2010 y aceptado para su publicación por el Comité Editorial el 28 de mayo de 2010. 


\section{INTRODUCCIÓN}

$\mathrm{E}$ n doctrina se entiende por estafa triangular o en triángulo aquélla en que el engañado realiza una disposición que no tiene efectos perjudiciales sobre su propio patrimonio, sino sobre uno distinto. $\mathrm{O}$, visto desde la perspectiva de la protección patrimonial, aquélla en que la disposición perjudicial no la realiza el titular del patrimonio afectado sino un tercero engañado. La admisibilidad conceptual de una estafa triangular surge del amplio consenso, tanto en Chile como en el extranjero, en torno a que el tipo de estafa sólo exige identidad entre engañado y disponente, pero no entre disponente y perjudicado, abriéndose en consecuencia la posibilidad de que el primero sea un tercero distinto del titular ${ }^{1}$.

No obstante este amplio reconocimiento inicial, los alcances exactos de la estafa triangular distan de estar totalmente resueltos. Particularmente en Chile, existe un conjunto de cuestiones problemáticas de la figura que hasta ahora no han sido objeto de discusión académica. La principal de ellas dice relación con los presupuestos bajo los cuales la actuación de un tercero que no es titular del patrimonio afectado puede considerarse disposición típica en los términos de la estafa, cuestión que suele resolverse a partir de la definición del tipo de relación que debe existir entre el tercero disponente y el patrimonio perjudicado. Este trabajo pretende proponer respuestas para ésta y otras cuestiones asociadas en el marco del derecho chileno, en especial, al final del trabajo, para las referidas al que probablemente sea el caso más significativo de estafa en triángulo, la llamada estafa procesal.

Para efectos de análisis conviene considerar por separado los dos grandes grupos de casos que han dominado la discusión comparada, por un lado los casos en que la disposición patrimonial consiste específicamente en la entrega de una determinada cosa corporal mueble (dando lugar a la llamada "estafa de cosas") y, por otro, los demás casos de disposición patrimonial (conocidos como casos de "estafa de pretensiones o derechos"). Desde luego todo indica que si el problema de fondo es el mismo la solución dogmática de todos los casos debe ser también la misma, con lo que la distinción se torna innecesaria y hasta perjudicial para la debida comprensión del asunto. Si no obstante se insiste en una revisión por separado es porque facilita la exposición y la comprensión del contexto y alcance específicos de los argumentos en debate, muchos de los cuales sólo tienen

${ }^{1}$ En Chile Etcheberry, A., Derecho penal, $3^{\text {a }}$ edición, Editorial Jurídica de Chile, Santiago, 1998, T. III, p. 398; Garrido, M., Derecho penal, Editorial Jurídica de Chile, Santiago, 2000, T. IV, pp. 328, 329 y s.; Politoff, S., Matus, J. P., Ramírez, M. C., Lecciones de derecho penal chileno. Parte especial, $2^{\text {a }}$ edición, Editorial Jurídica de Chile, Santiago, 2005, p. 421; Hernández, H., “Aproximación a la problemática de la estafa”, en AA. VV., Problemas actuales de derecho penal, Universidad Católica de Temuco, Temuco, 2003, p. 156; de otra opinión sólo Piña, J. I., Fraude de seguros, Universidad de los Andes, Santiago, 2005, pp. 45 y s., 76 y s., quien la califica de construcción inconsistente y artificiosa. En España (donde el art. 248 CP se refiere expresamente a la obtención de un acto de disposición "en perjuicio propio o ajeno"), por todos, Bajo Fernández, M., Los delitos de estafa en el Código penal, Editorial Universitaria Ramón Areces, Madrid, 2004, p. 48 y s. En Alemania, por todos, Tiedemann, K., “\$ 263”, en Leipziger Kommentar zum Strafgesetzbuch (LK), 11. Aufl., De Gruyter, Berlin-New York, 1999, marg. 112 y ss. 
sentido -o lo tienen predominantemente- respecto de uno de los grupos y, por lo tanto, se han desarrollado sólo a su respecto. Con todo, en las sucesivas tomas de posición se tiene siempre en cuenta la necesidad de un tratamiento esencialmente unitario.

\section{Disposición sobre cosas Corporales muebles (ESTAFA DE COSAS)}

El caso de estafa triangular más tratado en la literatura es aquél en el que la disposición del engañado consiste en la entrega de una cosa corporal mueble ajena, con el consiguiente perjuicio patrimonial para el dueño de la misma. Ahora bien, en la medida en que la apropiación de cosas corporales muebles sin el consentimiento de su dueño constituye por regla general a lo menos hurto, lo que está en juego en términos prácticos con la definición precisa de los presupuestos de una disposición típica a título de estafa (que sería la antítesis de una apropiación no consentida) ${ }^{2}$ no es, o al menos no en principio, la punibilidad misma de la conducta, sino fundamentalmente la delimitación entre estafa y burto 3 por autoría mediata.

La punibilidad de la conducta sólo puede estar en duda, por una parte, en los casos en que no obstante darse la estructura de la estafa y no la del hurto, se sostenga que ésta no satisface las exigencias del engaño típico propio de aquélla ${ }^{4}$, sea porque carece objetivamente de relevancia negocial ${ }^{5}$, sea porque carece del grado de calificación que exige la opinión todavía dominante en nuestra doctrina ${ }^{6}$. Por la otra, en los casos en que afirmada la estructura del hurto, el agente sólo ha querido usar transitoriamente la cosa (hurto de uso atípico). Más allá de esos límites las consecuencias de la distinción serán de carácter fundamentalmente penológico, pues si bien desde 1959 las penas del hurto y de la estafa están en general equiparadas (cfr. arts. 446 y 467) ${ }^{7}$, la penalidad del hurto es potencialmente mayor, tanto porque a su respecto rigen agravantes especiales que no rigen para la estafa (art. 456 bis), porque el hurto mediante engaño bajo ciertas

\footnotetext{
${ }^{2}$ Como se ve, aquí se asume la incompatibilidad conceptual entre hurto y estafa, concepción que, si bien es dominante en la discusión comparada, es puesta en duda cada cierto tiempo. Así, por ejemplo, Herzberg, R., "Betrug und Diebstahl durch listige Sachverschaffung", en ZStW, 89, 1977, 367 passim.

${ }^{3} \mathrm{O}$ robo con fuerza en las cosas en algún supuesto particular de acuerdo con el art. $440 \mathrm{~N}^{\circ} 3 \mathrm{CP}$.

${ }^{4}$ Walter, T., Betrugsstrafrecht in Frankreich und Deutschland, C.F. Müller, Heidelberg 1999, p. 212 y s., da cuenta de cómo en Francia la delimitación entre estafa de cosas y hurto suele resolverse precisamente en favor del hurto por la exigencia de engaño calificado que rige en ese país, no obstante que el criterio concursal decisivo es el de la pena y en Francia - a diferencia de lo que ocurre potencialmente en Chile, como se expone en seguida en el texto- la estafa tiene asignada mayor pena.

${ }^{5}$ Al respecto Hernández, H., "Normativización del engaño y nivel de protección de la víctima en la estafa: lo que dice y no dice la dogmática”, en Revista Chilena de Derecho, Vol. 37, 2010.

${ }^{6}$ Sobre la concepción dominante, Hernández, “Aproximación”, p. 160 y ss.

${ }^{7}$ Recuérdese que en el Código original, si bien las cuantías determinantes y las penas de presidio previstas eran -como ahora- las mismas para ambos delitos, en el caso de la estafa se consideraba la relegación como alternativa al presidio, con lo cual, al menos desde un punto de vista legislativo, la penalidad de la estafa era sensiblemente menor. Sólo con la supresión de esa alternativa mediante la Ley No 13.303 , de 31 de marzo de 1959, se equipararon plenamente los marcos penales generales, equiparación que rige hasta hoy.
} 
condiciones puede calificarse como robo con fuerza en las cosas (art. $440 \mathrm{~N}^{\circ} 3$ ), con una pena considerablemente mayor, porque el hurto seguido del ejercicio de violencia o intimidación para procurar la impunidad no queda sujeto a las reglas concursales generales, sino que se califica, con un aumento radical de la pena, como robo con violencia o intimidación (art. 433 inciso primero), en estos dos últimos casos, además, con alteración de las reglas de iter criminis (art. 450 inciso primero), como porque el régimen especial de la llamada estafa residual del art. 473 sitúa las penas de esta última en el límite inferior de las penas del hurto.

Como ya se ha adelantado, la discusión se centra en el tipo de relación que debe existir entre el disponente y el patrimonio perjudicado para afirmar la presencia de una estafa. El supuesto indiscutido es el del tercero engañado que dispone en representación del titular del patrimonio, porque de lo contrario habría que arribar a la conclusión absurda de que las personas que deben actuar representadas, paradigmáticamente las personas jurídicas, no pueden ser víctimas de estafa. Tan claro es el punto que incluso el recurso al concepto mismo de estafa triangular para abordarlo puede parecer innecesario. En todo lo demás, en cambio, la situación es muy discutida en el derecho comparado. Con prescindencia de múltiples cuestiones de detalle, el debate ha sido caracterizado en lo fundamental como una oposición entre quienes exigen que el disponente actúe con un poder jurídico de disposición y aquéllos que consideran suficiente un simple poder fáctico.

Por la primera opción, conocida como "teoría de la facultad", se decanta la doctrina dominante en España ${ }^{8}$ y en Italia ${ }^{9}$, así como la opinión minoritaria en Alemania. Si bien en general se va más allá de los casos estrictos de disposición en representación del titular de la cosa, se exige la existencia de una legitimación jurídica para disponer de la misma, sea por algún poder otorgado por el titular (Ermächtigungstheorie), sea por una competencia emanada de la ley o de un acto de la autoridad (Befugnistheorie) ${ }^{10}$. En la medida en que nadie discute que en estos casos la disposición del tercero es disposición típica en los términos de la estafa, en rigor la discusión gira en torno a si es posible ir más allá de esos límites y, en caso afirmativo, hasta dónde se puede llegar.

${ }^{8}$ Así Pastor Muñoz, N., La determinación del engaño típico en el delito de estafa, Marcial Pons, MadridBarcelona, 2004, pp. 68 con nota 60, 80 con nota 8, 174 con nota 24 y 178 con nota 44; Bacigalupo, E., Falsedad documental, estafa y administración desleal, Marcial Pons, Madrid-Barcelona-Buenos Aires, 2007, p. 174; Choclán Montalvo, J. A., El delito de estafa, 2a edición, Bosch, Barcelona, 2009, p. 190; en contra podría considerarse a Valle Muñiz, J. M., El delito de estafa, Bosch, Barcelona, 1987, p. 223, en cuanto no ve razones para restricciones adicionales, si bien el autor manifiestamente confunde el asunto con el de si hay o no traspaso de custodia. En Argentina Romero, G., Delito de estafa, $2^{a}$ edición, Hammurabi, Buenos Aires 1998 , p. 238 se decanta por el simple poder de hecho (no así en la estafa de derechos).

9 De Francesco, G., “Art. 640”, en Crespi, A., Stella, F., Zuccalà, G. (editores), Commentario breve al Codice penale, CEDAM, Padova, 1992, marg. 15 (p. 1499).

${ }^{10}$ En alemán la distinción sirve de base para una denominación diferenciada. Si bien en castellano también se podría distinguir, probablemente entre teoría del encargo o del poder y teoría de la autorización, se ha preferido la expresión genérica "teoría de la facultad", no sólo porque los términos disponibles en nuestra lengua no expresan una distinción tajante, sino sobre todo porque la distinción carece de relevancia práctica (en general no se sostiene una tesis tan restrictiva circunscrita al encargo del titular), como lo demuestra que en el debate alemán o sólo se emplee un término o se empleen ambos como sinónimos. 
Si bien a estas alturas los matices dificultan una clara delimitación en su interior, se puede decir que la opinión dominante en Alemania adhiere a la llamada "teoría del campo" (Lagertheorie), más moderada y abierta a consideraciones normativas que otras posiciones que en el pasado apenas exigían algo más que una mera cercanía fáctica ${ }^{11}$. Esta doctrina exige, además de dicha cercanía fáctica, que el tercero engañado se ubique en -o forme parte del- "campo" del titular del patrimonio. En otras palabras, que pertenezca al mismo círculo de poder del que proviene la cosa ${ }^{12}$. Esto se da cuando tiene la custodia -exclusiva o compartida- de la cosa o bien cuando, aun sin tener su custodia, se encuentra en una posición de vigilancia o protección de la misma. Mayoritariamente se exige, además, en el plano subjetivo, la representación de estar obrando en interés y de acuerdo con la voluntad del titular del patrimonio. Desde luego bajo cualquiera de estos conceptos están también cubiertas todas las hipótesis relevantes conforme a la teoría de la facultad, pero resultando indiferente su diverso status normativo ${ }^{13}$.

Antes de adoptar y justificar una posición al respecto cabe hacer presente que el debate se ha visto en cierto modo enturbiado por consideraciones que no parecen apuntar al meollo de la cuestión. Así, por una parte, éste se ha visto envuelto en una disputa más amplia sobre el predominio de los criterios fácticos o normativos en la dogmática de la estafa, como lo confirma la importancia que se le suele asignar en dicho debate al punto de vista que se sostenga en cuanto al concepto -más o menos normativo, más o menos fáctico- de patrimonio y de perjuicio patrimonial, como si de dicha toma de posición debiera fluir natural y necesariamente la respuesta a la cuestión del vínculo entre disponente y titular del patrimonio en la estafa triangular ${ }^{14}$. Por otra parte, la aparición de posibles lagunas de punibilidad parece haberse erigido en criterio excesivamente relevante para adoptar una u otra tesis.

${ }^{11}$ La llamada "teoría de la cercanía" (Nähetheorie) atendía a un criterio estrictamente fáctico de disponibilidad sobre la cosa, sólo restringido -porque, como destaca Küper, W., Strafrecht BT, 6. Aufl., C.F. Müller, Heidelberg, 2005, p. 391, de lo contrario sería imposible distinguir entre estafa triangular y hurto por autoría mediata, ya que el mero instrumento de la apropiación, por definición, tiene poder fáctico de disposición-mediante la exigencia de un grado mayor de cercanía con el objeto que el que tendría "cualquier tercero ajeno" y que se expresa en el dato cronológico de que ya antes del engaño el disponente hubiera estado en condiciones de disponer del mismo. En la actualidad, sin embargo, no obstante muchos autores siguen distinguiendo entre ambas aproximaciones (e incluso alguno sigue considerando que ésta es la dominante en la jurisprudencia), ésta parece haber sido absorbida como punto de partida de la "teoría del campo".

${ }^{12}$ La formulación original proviene de un artículo de Horst Schröder ("Über die Abgrenzung des Diebstahls von Betrug und Erpressung", en $Z S t W, 60,1941$, p. 33 y ss.), en tanto que la denominación estándar proviene de un comentario de jurisprudencia de Theodor Lenckner (en JZ, 1966, p. 319 y ss., comentario sobre fallo del OLG Stuttgart de14 de julio de 1965). Ninguno de los dos se ha podido tener a la vista.

${ }^{13}$ Por todos Tiedemann, LK $\$ 263$ marg. 116.

${ }^{14}$ Así, entre otros, enfáticamente Lackner, K., “\$ 263”, en Leipziger Kommentar zum Strafgesetzbuch (LK), 10. Aufl., De Gruyter, Berlin-New York, 1979, marg. 113; Wessels, J., Hillekamp, T., Strafrecht BT 2, 29. Aufl., C.F. Müller, Heidelberg, 2006, § 14 marg. 639; Joecks, W., Zur Vermögensverfügung beim Betrug, Dr. Peter Deubner, Köln, 1982, p. 125. 
Desde luego se trata de consideraciones de la mayor importancia, pero que no autorizan a perder de vista que lo que está en juego aquí no es el carácter más o menos normativo del concepto de patrimonio ni la forma de "cubrirle las espaldas" al hurto, sino un asunto completamente diferente, como es si y bajo qué supuestos es posible imputar la disposición perjudicial del tercero engañado al titular del patrimonio como si él mismo la hubiera realizado ${ }^{15}$, como corresponde al carácter de la estafa como delito de autolesión. De lo que se trata, en consecuencia, es de preservar en estas hipótesis la diferenciación fundamental entre el hurto como delito de heterolesión ("sin la voluntad del dueño") y la estafa como delito de autolesión (disposición patrimonial como voluntad del dueño o de alguien que actúa por él). Esto rige tanto si se sostiene un concepto radicalmente económico o jurídico de patrimonio y debe mantenerse aunque eventualmente puedan surgir vacíos de punibilidad más o menos indeseables, no sólo porque esto sea consecuencia de la opción legislativa por una protección sólo fragmentaria del patrimonio, sino además porque lo contrario implicaría degradar conceptualmente la estafa a una mera figura genérica y residual del hurto.

Desde esa perspectiva el punto de partida correcto debería ser el de la teoría de la facultad, la única que explica de modo convincente por qué el titular del patrimonio debe aceptar que se le impute como disposición propia el comportamiento de un tercero ${ }^{16}$. Esto es posible no porque el tercero se encuentre "más cerca" de la cosa y haya podido en los hechos disponer de ella, sino porque en virtud de la facultad no sólo dispone, sino que lo hace por el titular.

Asumido este punto de partida, lo único discutible debería ser el grado de apego a las reglas del derecho privado vigente ${ }^{17} \mathrm{o}$, más bien, el grado de rigor en la interpretación de dichas reglas, que debe observarse a la hora de comprobar si el tercero engañado estaba facultado o no para realizar la disposición. Si bien algunos partidarios de la teoría de la facultad abogan por una accesoriedad estricta a las reglas jurídicas del derecho privado ${ }^{18}$,

\footnotetext{
${ }^{15}$ Titular y tercero disponente deben formar una "unidad de imputación”, debe haber entre ellos una "identidad relativa", entre otras expresiones equivalentes.

${ }^{16}$ Así Kindhäuser, U., Strafgesetzbuch. Lehr- und Praxiskommentar (LPK), 1. Aufl., Nomos, Baden-Baden 2002, marg. 151, si bien ahora se decanta por un criterio radicalmente fáctico: Kindhäuser, U., “\$263”, en Nomos-Kommentar zum Strafgesetbuch (NK), 2. Aufl., Nomos, Baden-Baden, 2005, marg. 220 y s.

${ }^{17}$ Los casos en que la facultad está asociada al ejercicio de una función pública se analizan conjuntamente infra IV.

${ }^{18}$ Es el caso especialmente de Backmann, L., Die Abgrenzung des Betrugs von Diebstabl und Unterschlagung, Heymanns, Köln etc., 1974, p. 127 y ss., quien exige facultades para transferir el dominio, lo que consecuentemente implica un apego radical al derecho privado; y en menor medida de Joecks, Zur Vermögensverfügung, p. 130 y ss., si bien sus resultados restrictivos parecen provenir más de su exigencia de "facultad para usar el patrimonio" que de una dependencia fuerte del derecho privado. En el derecho positivo chileno puede verse un argumento en favor no sólo de la teoría de la facultad, sino que incluso de una comprensión restrictiva de la misma, en la regulación del robo con fuerza en las cosas en lugar habitado o destinado a la habitación o en sus dependencias, específicamente en el $\mathrm{N}^{\circ} 3$ del art. $440 \mathrm{CP}$, donde se califica como fuerza en las cosas el ingreso al lugar o dependencia "mediante la seducción de algún doméstico", entendiéndose por tal el ingreso mediante engaño en cuanto a los verdaderos propósito del sujeto (así Labatut, G., Derecho penal, T. II, $7^{a}$ edición, Editorial Jurídica de Chile, Santiago, 1983, p. 208; Etcheberry, T. III, p. 329; Garrido, T. IV,
} 
la mayoría de sus seguidores, sin embargo, parece inclinarse por una consideración menos rígida de las mismas, empleándolas más como modelos plausibles de imputación que como normas de aplicación pertinente ${ }^{19}$, lo que parece correcto ${ }^{20}$.

Sin perder de vista el criterio clave de la facultad, puede sostenerse que para los fines del derecho penal puede ser suficiente una posición analogable a aquéllas en que existe una facultad formalmente constituida conforme a reglas jurídicas, aunque su validez a luz de dichas reglas pueda ser discutible. Tal como la ley reconoce que la gestión de negocios ajenos sin que medie mandato de ningún tipo y aun sin conocimiento del interesado puede ser fuente de obligaciones para éste (art. 2286 y ss. CC), así también, al menos para los fines del derecho penal, puede bastar para la imputar la disposición al titular del patrimonio, por ejemplo, con una cierta tolerancia previa de su parte al mismo tipo de disposiciones o con una determinada forma de organización que las haga previsibles y aceptables ${ }^{21}$. En último término, tampoco es tarea de la interpretación del tipo de estafa, concretamente en lo concerniente a la estafa triangular, preservar los alcances exactos que en sus ramas de origen tienen las reglas de competencia sobre

p. 230 y s.; Politoff, Matus, Ramírez, PE, p. 345). Al margen de cualquier valoración de la disposición, que no se encontraba en el modelo español ni respecto de la cual quedara algún comentario en las Actas de la Comisión Redactora, no puede desconocerse que ésta muestra con toda nitidez el recelo del legislador chileno hacia las atribuciones del servicio doméstico. Y si bien la norma sólo describe una forma engañosa de ingreso al lugar, dejando sin resolver si la entrega de la cosa por parte del propio doméstico obtenida mediante engaño es o no la consumación de un acto de apropiación, parece poco plausible sostener que la entrega de una cosa por parte de un empleado no habilitado siquiera para dejar entrar a alguien a la casa, pueda serle imputable al titular del patrimonio como disposición propia. Con todo, como se señala en el texto, si el empleado doméstico cuenta efectivamente con ciertas facultades de disposición sobre cierto tipo de objetos, no parece que el argumento legal permita negar en ese ámbito la existencia de una disposición típica a título de estafa.

19 Así Otto, H., "Zur Abgrenzung von Diebstahl, Betrug und Erpressung bei der deliktischen Verschaffung fremder Sachen”, en $Z S t W, 79,1967$, p. 84 y s., cuya propuesta normativa (en base a "posiciones de disposición”) prescinde al menos formalmente de las categorías del derecho civil; Schünemann, B., "Methodenprobleme bei der Abgrenzung von Betrug und Diebstahl in mittelbarer Täterschaft", en GA, 1969 , p. 53 y s., para quien el derecho civil representaría el orden de valores al que debe orientarse el derecho penal "si bien en parte con modificación o sustitución de los acentos valorativos", para lo cual, junto con el concepto de "representación en la custodia", brinda ejemplos en la línea de lo sostenido en el texto; Krey, V., Hellmann, U., Strafrecht BT 2, 13. Aufl., Kohlhammer, Stuttgart, 2002, § 11 marg. 417 y s.; al parecer también, sin perjuicio de acentuar la relevancia del derecho privado Amelung, K., "Irrtum und Zweifel des Getäuschten beim Betrug”, en GA, 1977, p. 14 y s.; Samson, E., “\$ 263”, en Systematischer Kommentar zum Strafgesetzbuch (SK), 20. Lfg., Luchterhand, Frankfurt a. M. 1986, marg. 94 y ss. (y ahora Hoyer, A., "\$ 263”, en Systematischer Kommentar zum Strafgesetzbuch [SK], 6. Aufl., Luchterhand, Köln, 2003, marg. 145 y ss.); Hefendehl, R., “\$ 263”, en Münchener Kommentar zum Strafgestzbuch (MüKo), Beck, München, 2006, marg. 288; Mitsch, W., Strafrecht BT 2, 2. Aufl., Springer, Berlin etc., 2003, § 7 marg. 74.

${ }^{20}$ Muy crítico en una época, en cambio, Kindhäuser, U., "Täuschung und Wahrheitsanspruch beim Betrug”, en $Z S t W, 103,1991$, p. 417 y ss.

${ }^{21}$ No está de más recordar que el Código Civil reconoce la existencia de cuasicontratos innominados, en la medida en que en el Título XXXIV del Libro IV, luego de definirlos, regula sólo los que denomina los tres "principales" (art. 2285 CC). 
bienes $^{22}$, sino sólo, como se ha dicho insistentemente, garantizar el carácter de delito de autolesión del tipo y -asegurado esto- hacerlo del modo más eficiente posible sin incurrir en contradicciones abiertas con el orden jurídico-civil.

Es lo que decididamente hace Offermann-Burckart en su monografía sobre el tema, cuando a partir de las valoraciones subyacentes en dos figuras del derecho civil alemán -y no a partir de las regulaciones mismas, que no son en sí pertinentes para la estafa triangular- desarrolla unos presupuestos propiamente penales para imputar la disposición del tercero al titular del patrimonio en los términos de la estafa ${ }^{23}$. Si bien puede parecer excesivo sostener -como hace la autora a partir de la muy intensa protección del adquirente de buena fe en el derecho civil alemán ${ }^{24}$ - que cualquiera que consciente y voluntariamente transfiere a otro un poder fáctico de disposición sobre una cosa debe contar con que éste puede disponer de ella aun contra su voluntad expresa ${ }^{25}$, se produce luego una rectificación cuando ese punto de partida se complementa con los criterios de la agencia oficiosa "justificada" ${ }^{26}$, de modo que sería disposición patrimonial típica la realizada por aquél a quien el titular ha transferido consciente y voluntariamente el poder fáctico sobre la cosa y que -de haber sido ciertas las afirmaciones del autor- habría correspondido a la voluntad efectiva o presunta del titular o, en último término, a sus intereses objetivos ${ }^{27}$. Es sobre todo esta última exigencia, que aquí se asume expresamente como correcta, la que permite decir con razonable propiedad que existe una "identidad relativa" entre titular y disponente, que forman una "unidad de imputación" para los fines de la estafa, sin llegar al extremo de exigir un idéntico grado de conocimiento de las circunstancias del caso $^{28}$.

${ }^{22}$ Se trata en definitiva de la autonomía relativa de la formación de los conceptos jurídico-penales. Así, en clave fáctica, Dreher, E., "Das Strafrecht hat seine eigene Methode”, en GA, 1969, p. 58; en clave normativista Pawlik, M., Das unerlaubte Verbalten beim Betrug, Heymanns, Köln etc., 1999, p. 215.

23 Offermann-Burckart, S., Vermögensverfügungen Dritter im Betrugstatbestand, Duncker \& Humblot, Berlin, 1994, p. 148 y ss.

${ }^{24}$ Punto de partida de la autora es el $\S 932$ BGB que dispone que el adquirente de buena fe efectivamente adquiere el dominio por tradición aunque el que transfiere no sea dueño, a menos que la cosa haya sido hurtada o robada (o de algún otro modo arrebatada) al titular o se le haya perdido (§ 935 BGB). De esta regulación colige que la ley le endosa al dueño la responsabilidad de elegir bien a aquéllos a quienes entrega la posesión de la cosa, porque en caso de abuso por parte de éstos se prefiere proteger al adquirente de buena fe. En la estafa obviamente el adquirente no está de buena fe, pero lo verdaderamente relevante para nuestros fines sería el criterio de imputación que fluye de las relaciones internas entre dueño y poseedor. A partir de ahí la autora va ampliando el criterio, desde la transferencia de posesión hasta la transferencia de un simple poder fáctico sobre la cosa (Offermann-Burckart, Vermögensverfügungen, p. 149 y ss.). El razonamiento ciertamente no parece ser de recibo en el derecho chileno, dada la protección mucho más circunspecta del adquirente de buena fe (sólo posibilidad de prescripción adquisitiva ordinaria o extraordinaria). De ahí que el poder fáctico sobre la cosa sólo pueda considerarse presupuesto para el genuino criterio de imputación, que sería la lógica de la agencia oficiosa.

${ }^{25}$ Offermann-Burckart, Vermögensverfügungen, pp. 152, 157, entre otras.

26 Offermann-Burckart, Vermögensverfügungen, p. 162 y ss.

27 Offermann-Burckart, Vermögensverfügungen, p. 169.

${ }^{28}$ Como hacía en su momento Kindhäuser, "Täuschung”, p. 420 y ss., al negar estafa en todos los casos de simple aprovechamiento de diferencias contingentes de conocimiento entre titular y disponente 
Los resultados deberían ser en lo fundamental coincidentes también con los propuestos por Pawlik desde su particular concepción teórica de la estafa. Este autor considera engaño típico sólo el dirigido a -y, consecuentemente, considera disposición típica sólo la efectuada erróneamente por- un tercero con la competencia para recibir y enjuiciar en lugar del titular del patrimonio las declaraciones del autor ${ }^{29}$, competencia que, en cuanto expresión de la necesaria autovinculación del titular, surge o bien del ejercicio por parte de éste de su libertad de organización, o bien de las condiciones institucionales que hacen posible dicho ejercicio y que consecuentemente debe asumir ${ }^{30}$. Pues bien, en el primer grupo, junto a los casos no problemáticos de acuerdo expreso, vienen en consideración fundamentalmente competencias derivadas del rol profesional o laboral que el tercero representa en el esquema de organización del titular del patrimonio ${ }^{31}$ e incluso, en ámbitos menos estandarizados, del reparto de competencias que en concreto se ha producido entre los sujetos ${ }^{32}$.

$\mathrm{Y}$ es lo que tendencialmente parece subyacer al planteamiento de un partidario de la teoría del campo como Rengier cuando, bajo una apelación algo difusa a los criterios de la imputación objetiva, sostiene que deberían imputarse al ámbito de responsabilidad del titular sólo aquellas disposiciones de terceros que, conforme a las circunstancias concretas y a la experiencia, deben calcularse y asumirse cuando se admite a dichos terceros en las cercanías del propio patrimonio ${ }^{33}$.

Como se ve, de este modo se produce en los resultados un relativo acercamiento con las posturas que enfatizan el aspecto fáctico de la disposición. Lo relevante, sin embargo, es que la coincidencia de resultados sólo implica verdadera convergencia cuando se tiene en mente no ya la cercanía ni la pertenencia a cierto círculo de personas sino, como hace Rengier, la necesidad de razones para imputarle al titular como propia una disposición ajena, razones que sólo aporta la teoría de la facultad. Por lo mismo, si bien la afirmación de una facultad en el caso concreto no está exenta de dificultades, de todos modos éstas son menores que las que debe enfrentar la teoría del campo, porque en la medida en que la simple "pertenencia" no dice nada respecto del problema de fondo, no existe un criterio orientador para superar su ambigüedad inherente ${ }^{34}$.

(al exigir vulneración de una pretensión de veracidad del titular, sólo podía ser relevante el engaño del disponente que lo hubiera sido también del titular con su concreto grado de conocimiento, al punto que "desde afuera" resultaba del todo equivalente engañar al uno o al otro). Al margen de la drástica reducción de la estafa triangular, la aplicación del criterio incluso a representantes jurídicamente constituidos resulta contraintuitiva al menos desde el punto de vista del sentido y función de la representación. Crítico también, a partir de la esencia de la división del trabajo, Pawlik, Das unerlaubte Verbalten, p. 217 y s.

29 Pawlik, Das unerlaubte Verhalten, p. 205 y ss.

30 Pawlik, Das unerlaubte Verbalten, p. 207.

31 Pawlik, Das unerlaubte Verbalten, p. 209.

32 Pawlik, Das unerlaubte Verbalten, p. 210.

33 Rengier, R., Strafrecht BT 1, 8. Aufl., Beck, München 2006, § 13 marg. 47.

34 Sin duda la teoría que menos dificultades prácticas plantea es la de la cercanía, porque virtualmente no hay nada que delimitar. Como se ha dicho, sin embargo, esto es a costa del carácter de delito de autolesión de la estafa. 
Ahora bien, la teoría de la facultad no puede entenderse en un sentido absolutamente objetivo, pues de lo contrario estaría condenada a la inoperancia práctica. En efecto, en caso de engaño la regla será que falten -porque sólo habrán sido simulados- los presupuestos objetivos para el ejercicio de la facultad, de modo que la disposición necesariamente se habrá efectuado al margen de las facultades otorgadas. De ahí que la única manera razonable de aplicar la teoría sea subjetivizándola, en el sentido de entender que se cumplen sus requisitos cuando en el caso concreto el sujeto cree estar actuando dentro del marco de sus atribuciones ${ }^{35}$. Esto no implica, sin embargo, terminar abrazando en los hechos una teoría como la del campo, que se satisface con la mera convicción indiferenciada del tercero de estar actuando legítimamente, porque lo que se exige en particular es la convicción de estar actuando dentro del marco de las facultades que objetivamente le han sido, en efecto, conferidas ${ }^{36}$.

Para explicarlo sirve el ejemplo propuesto por Kindhäuser en su crítica a esta subjetivización necesaria. Se trata del vecino a quien en vacaciones se le entregan las llaves de la casa para que encienda las luces, riegue las plantas o recoja la correspondencia. En ese contexto se le presenta un sujeto que se hace pasar por amigo de los dueños de casa y simula haber recibido de éstos el encargo de retirar un determinado objeto, a lo que el vecino accede, creyendo que en una situación así está facultado para entregar el objeto. Si efectivamente bastara con la creencia del vecino de estar obrando justificadamente para considerar que su entrega constituye disposición patrimonial típica en los términos de la estafa, tendría razón Kindhäuser en cuanto a que esta variante subjetivizada de la teoría de la facultad no se apartaba demasiado de la teoría del campo ${ }^{37}$. La situación es bien distinta, sin embargo, si se considera que la creencia relevante del tercero que dispone es sólo aquélla que versa sobre la concurrencia en concreto de los requisitos de una disposición del tipo de aquéllas que objetivamente sí están cubiertas por la facultad. De este modo, en el ejemplo no se puede imputar la disposición al titular, cualesquiera que sean las representaciones del vecino a cargo, por la sencilla razón de que éste carece de atribuciones para entregar objetos. Distinto sería el caso cuando el vecino ha quedado con el encargo de entregar un objeto a un amigo del dueño de casa y lo entrega a quien se presenta simulando ser ese amigo, porque en esta hipótesis efectivamente la facultad existe, aunque en concreto se han falseado sus condiciones de procedencia ${ }^{38}$.

Conforme a una teoría de la facultad así entendida, además, por cierto, de los casos de encargo expreso o de actuación estandarizada por otro (dependientes de comercio, cajeros, etc.), debería imputársele, por ejemplo, a la dueña del automóvil la entrega del mismo por parte del cuidador del estacionamiento al antiguo conviviente de aquélla, pero sólo si en ocasiones anteriores ella al menos toleró que éste retirara el vehículo. Lo mismo debería regir respecto de las cosas entregadas por el servicio doméstico o de

\footnotetext{
${ }^{35}$ Küper, BT, p. 392.

${ }^{36}$ Hefendehl, MӥKo § 263 marg. 289.

${ }^{37}$ Kindhäuser, LPK § 263 marg. 150.

38 Así Hoyer, SK § 263 marg. 150; Hefendehl, MüKo § 263 marg. 289.
} 
secretaría cuando se trata de objetos que normalmente son entregados por ese personal bajo circunstancias típicas también concurrentes. No parece ser el caso, en cambio, al menos en principio, de la entrega de cosas de la arrendataria, pensionista o pasajera por parte del dueño o administrador de la casa, hotel o pensión.

Por último y como ya se dijo, existe amplio acuerdo en cuanto a que las disposiciones realizadas por un tercero que actúa en virtud de facultades otorgadas por la ley o la autoridad son disposiciones típicas en los términos de la estafa. Si hasta aquí, sin embargo, ese tipo de casos no ha sido mayormente tratado se debe a que su campo de aplicación principal no es el de la estafa de cosas. En efecto, comparativamente los casos en que lo que se obtiene mediante engaño de la autoridad competente es que ésta ordene la entrega de una determinada cosa corporal mueble ${ }^{39}$ son muy minoritarios. Generalmente la llamada "estafa procesal” y las figuras análogas dan lugar a otras formas de afectación patrimonial, razón por la cual su tratamiento se reserva para los casos de otras disposiciones patrimoniales (infra III) y, especialmente, para la consideración particular de la estafa procesal (infra IV).

\section{OTRAS DISPOSICIONES PATRIMONIALES \\ (ESTAFA DE PRETENSIONES O DERECHOS)}

No sólo respecto de la entrega de cosas corporales muebles se requiere que el tercero disponente se encuentre en una posición que permita imputarle su conducta al titular del patrimonio como acto propio de disposición. Si se quiere preservar el carácter de delito de autolesión de la estafa, lo mismo debe regir a la hora de admitir una disposición patrimonial típica cuando el tercero le irrogue con su conducta un perjuicio, sea disponiendo de valores patrimoniales (incluyendo créditos) que le corresponden, sea imponiéndole obligaciones o gravámenes.

En estos casos no está en juego la delimitación entre la estafa y el hurto, lo que al mismo tiempo implica que la negación del carácter típico de la disposición acarrea la impunidad de la conducta, a menos que casualmente se verifiquen los presupuestos de algún tipo especial. Por cierto es indudable que no por ello puede prescindirse de esta exigencia estructural de la estafa ${ }^{40}$, pero es muy probable que dicha circunstancia haya incidido en una aproximación en general poco exigente a la hora de comprobar una estafa en triángulo. En todo caso se trata de una cuestión bastante descuidada por la literatura. Hasta donde se ve, por ejemplo, la doctrina española no parece haberse preocupado ma-

39 Por ejemplo, la entrega compulsiva de la cosa en el contexto de un juicio ejecutivo de obligaciones de dar que recae, además, sobre una especie o cuerpo cierto mueble.

${ }^{40}$ En esto existe hoy cierto consenso: Samson, SK § 263 marg. 67 a, 98; Joecks, Zur Vermögensverfügung, pp. 42 y ss., 84 y ss.; Tiedemann, LK § 263 marg. 117; Hefendehl, MüKo § 263 marg. 290. 
yormente del asunto ${ }^{41}$, en tanto que en Alemania su tratamiento es considerablemente más pobre que el que se le ha dado a la estafa de cosas.

Tal como respecto de la estafa de cosas, para que la disposición patrimonial del tercero pueda ser imputada como propia al titular del patrimonio afectado, aquél debe contar con alguna facultad para incidir en un patrimonio ajeno, facultad que puede provenir o bien de la voluntad del titular, o bien de la ley.

Evidentemente no plantean dificultades las actuaciones de los representantes ni de quienes en general y de modo estandarizado actúan por el titular del patrimonio (dependientes de comercio, cajeros, etc.), como cuando se paga un cheque falso, se cambia dinero falso, se emiten recibos o cancelaciones sobre la base de antecedentes falsos, se suscriben títulos de deuda, etc.

Tampoco deberían generar mayores problemas in puncto disposición patrimonial típica los casos en que el tercero engañado ejerce una autoridad en virtud de la cual posee la facultad de afectar las posiciones patrimoniales de las personas. El caso paradigmático es, por cierto, el de los jueces que pueden disponer directamente sobre el patrimonio de las partes y, con ello, además, de modo mediato, afectar también a terceros ajenos al procedimiento. Los únicos casos que deberían excluirse desde esta perspectiva deberían ser aquéllos en los que la autoridad o funcionario se aparten inequívocamente ${ }^{42}$ de sus facultades legales, porque entonces el efecto sobre el patrimonio afectado tendrá una base meramente fáctica que, conforme a lo que se viene sosteniendo, no permite imputarlo como propio al titular del patrimonio. En cualquier otro caso las cuestiones realmente discutibles son otras, no la imputación de la disposición del funcionario al titular del patrimonio, según se verá más tarde a propósito de la llamada estafa procesal (infra IV).

En este contexto cabe destacar todavía, sin embargo, una variante que sólo puede darse en los casos en que se discute la presencia de una estafa de pretensiones o derechos, como es que el perjuicio no derive de un acto de disposición directa sobre el patrimonio perjudicado, sino de una disposición realizada sobre un patrimonio distinto, respecto de lo cual la llamada estafa procesal ofrece espléndidos ejemplos, si bien a veces también puede tratarse de una disposición del engañado sobre su propio patrimonio.

Dos ejemplos de estafa procesal para graficarlo: en el primer caso el demandante obtiene, engañando al juez con pruebas falsas, la condena del demandado; en el segundo demandante y demandado simulan un juicio laboral por remuneraciones impagas, engañando de ese modo al juez, quien resuelve a favor del demandante y perjudica, a través del establecimiento del privilegio de que gozan las remuneraciones adeudadas (art. $2472 \mathrm{~N}^{\circ} 5 \mathrm{CC}$ ), el crédito de un tercero ajeno al juicio. En el primer caso el juez dispone directamente sobre el patrimonio perjudicado (el del demandado), gravándolo con una deuda hasta ahora inexistente. En el segundo caso, en cambio, el juez dispone sobre el patrimonio del demandado, pero el perjuicio lo sufre el patrimonio de un tercero

${ }^{41}$ En la Argentina Romero, Delito de estafa, p. 238, se decanta por la exigencia de una habilitación jurídica para disponer.

42 Esto es, más allá de cualquier disputa interpretativa sobre los alcances de sus facultades. 
totalmente ajeno al juicio. La cuestión es si también en este último grupo de casos se puede apreciar una estafa.

Hasta donde se ve, la cuestión no ha sido especialmente discutida en Chile, pero al menos Grisolía la responde en términos afirmativos, en la medida en que, si bien no tematiza el aspecto estructural, emplea como ejemplo e hilo conductor de su argumentación en favor de la tipicidad de la estafa procesal precisamente una hipótesis de juicio simulado $^{43}$. Y parece ser la respuesta correcta, atendido el reconocimiento general de la estafa triangular y la ausencia de restricciones legales a su concreta configuración. Las posibles reservas fundadas en el temor de que cualquier posible efecto perjudicial en algún patrimonio "en los alrededores" de aquél en que ha recaído la disposición dé lugar a una estafa ${ }^{44}$, deberían disiparse si se tienen en cuenta precisamente las exigencias que se vienen discutiendo respecto del tipo de vínculo que debe existir entre el disponente engañado y el titular del patrimonio perjudicado para que la conducta del primero sea imputable al segundo como acto propio de disposición ${ }^{45}$. En definitiva, tratándose tanto de disposiciones que recaen directamente sobre el patrimonio perjudicado como de disposiciones que recaen sobre un patrimonio distinto -sea el del propio disponente, sea el de un tercero- la pregunta fundamental para la afirmación de una estafa triangular es siempre la misma.

De ahí que sea más complicada la situación de aquellas disposiciones sobre patrimonio propio que simplemente resultan perjudiciales para otro. Tal sería el caso del empresario que en virtud de engaño decide contratar suministros con una empresa y no con otra, en condiciones que no le resultan perjudiciales. Desde luego puede ocurrir que en casos como éste la empresa desplazada no sufra perjuicio alguno, porque la posibilidad de celebrar el contrato no forma parte de su patrimonio. Pero con independencia de eso, aunque sí pudiera hablarse de la pérdida de una expectativa lo suficientemente concreta como para constituir patrimonio ${ }^{46}$, la cuestión sería en virtud de qué razones puede imputársele el contrato con la otra empresa como disposición propia a la empresa desplazada. Tratándose de una licitación o concurso, ese contexto específico todavía permitiría sostener que, al participar en el procedimiento, el participante desplazado ha aceptado los efectos que sobre su patrimonio deba tener la decisión que se adopte al respecto, de modo que la adjudicación fraudulentamente obtenida por otro participante puede imputársele como disposición propia a los efectos de la estafa ${ }^{47}$. En ausencia de

${ }^{43}$ Grisolía, F., "La estafa procesal en el derecho penal chileno", en Revista Chilena de Derecho, Vol. 24, 1997, 417 y ss. En esa medida también Politoff, Matus, Ramírez, PE, p. 422.

${ }^{44}$ Hernández, “Aproximación”, p. 157.

45 Además de las exigencias propias del concepto de perjuicio, que supone que el interés afectado pertenezca efectivamente al patrimonio en cuestión.

${ }^{46}$ No es posible desarrollar aquí mayormente el punto. Baste con consignar que se sostiene una concepción del patrimonio que entiende que forman parte del mismo las expectativas susceptibles de protección jurídica. Al respecto, en general, Hefendehl, R., Vermögensgefährdung und Exspektanzen, Duncker \& Humblot, Berlin, 1995 passim; en Chile Schlack, A., "El concepto de patrimonio y su contenido en el delito de estafa", en Revista Chilena de Derecho, Vol. 35, 2008, p. 281 y s.

${ }^{47}$ Offermann-Burckart, Vermögensverfügungen, p. 194 y s. 
un contexto de ese tipo, sin embargo, no parece posible seguir sosteniendo la conclusión. Resulta un exceso, por ejemplo, sostener genéricamente para estos efectos que el comerciante ha aceptado las consecuencias que sobre su patrimonio tenga la voluntad de los consumidores, de modo de poder imputarle las decisiones de éstos obtenidas mediante engaño ${ }^{48}$. Para afirmar una estafa triangular no puede bastar una suerte de "resignación universal" ante toda disposición patrimonial que pueda tener efectos en el propio patrimonio, lo que en rigor no sería más que hacer bastar el simple poder fáctico de irrogar perjuicios patrimoniales.

En principio parecería más convincente la inclusión de las disposiciones de un sujeto sobre su propio patrimonio que en virtud de la ley tienen efectos perjudiciales sobre el patrimonio de otro, como es el caso, por ejemplo, del deudor de buena fe que paga al falso acreedor que se encuentra en posesión del crédito y que, conforme al inciso segundo del art. 1576 CC, queda liberado de su obligación respecto del verdadero acreedor. Lo mismo cabría decir de otras hipótesis análogas ${ }^{49}$. Sin duda regulaciones como ésta establecen o refuerzan una conexión relevante entre la conducta del tercero disponente y el patrimonio perjudicado (es precisamente en virtud de ellas que se produce el perjuicio), lo que debería bastar para quienes exigen una cierta "cercanía" entre ambos extremos para afirmar una disposición patrimonial típica ${ }^{50}$. Desde el punto de vista que se ha asumido aquí, sin embargo, la cuestión es si esa cercanía permite hablar razonablemente del ejercicio de una facultad para actuar por el titular del patrimonio, de una unidad de imputación entre el tercero y dicho titular. Y todo parece indicar que no, atendido que se trata de reglas que no consideran en absoluto la situación del titular del patrimonio, sino exclusivamente la protección de la buena fe, la apariencia jurídica y la fluidez del tráfico económico ${ }^{51}$. Que desde la perspectiva de la protección penal del patrimonio y de su titular se trate de hipótesis que merecerían tanto o mayor protección es algo que ciertamente se puede compartir ${ }^{52}$, pero su tipicidad a título de estafa simplemente se opone el carácter de delito de autolesión del tipo.

Como se ve, si se asume consistentemente la teoría de la facultad, el ámbito de aplicación de la estafa de pretensiones o derechos es relativamente restringido, lo que en

48 Así, sin embargo, Offermann-Burckart, Vermögensverfügungen, p. 193 y s., con referencia a RGSt. 26, 227 (1894); Lackner, LK $\$ 263$ marg. 110 y ss.

49 Antonio Bascuñán Rodríguez ha propuesto entre nosotros el caso de los consumidores de un determinado servicio que en virtud de un engaño contratan con un proveedor no autorizado, en perjuicio del titular de un derecho de exclusividad para proveer dicho servicio. Si bien los consumidores no están obligados a contratar, si desean consumir sí estarían obligados a contratar con el proveedor exclusivo, de modo que la contratación con otro proveedor -supuesto que ese contrato eventual forma parte del patrimonio del proveedor exclusivo- sería un caso análogo al del inciso segundo del art. 1567 CC (Bascuñán, A., "Delito de estafa e intromisión fraudulenta en mercados regulados”, 2006, minuta inédita facilitada por su autor).

${ }^{50}$ Lackner, $L K \S 263$ marg. 115; Tiedemann, LK $\$ 263$ marg. 117; Rengier, BT 1, § 13 marg. 51 (lo niega en el caso del adquirente de buena fe, por falta de conexión previa, marg. 50).

${ }^{51}$ Joecks, Zur Vermögensverfügung, p. 133; Samson, SK § 263 marg. 98; Hefendehl, MüKo § 263 marg. 292; Offermann-Burckart, Vermögensverfügungen, pp. 197, 200, 203 y s.

52 Así Kindhäuser, NK $§ 263$ marg. 216; y antes ya, no obstante su adhesión a la teoría de la facultad, en lo que denominaba teoría de la efectividad, Kindhäuser, $L P K \S 263$ marg. 151. 
vez de conducir a una interpretación del tipo incompatible con su carácter de delito de autolesión debería servir de ocasión para la reflexión político-criminal y legislativa ${ }^{53}$.

\section{EN PARTiCular, LA ESTAFA PROCESAL}

\section{Concepto y reconocimiento general}

La estafa procesal se caracteriza porque el engaño se dirige contra un juez o funcionario del aparato de justicia, quien incurre en error y en dicha virtud resuelve en términos perjudiciales para el patrimonio de una de las partes o de un sujeto ajeno al procedimiento pero a quien los resultados de éste le empecen ${ }^{54}$.

La figura goza de amplio reconocimiento doctrinario y jurisprudencial en el derecho comparado. En el caso del derecho español se ha reconocido desde antiguo la posibilidad de una estafa procesal ${ }^{55}$. Más aún, el Código de 1995 la reconoce explícitamente erigiéndola ahora en un supuesto agravado de estafa ${ }^{56}$. En efecto, el $\mathrm{N}^{\mathrm{o}} 2$ del art. 250.1 $\mathrm{CP}$ dispone que el delito de estafa se sancione con una pena más grave que la prevista en el tipo base del art. $248 \mathrm{CP}$ cuando "se realice con simulación de pleito o empleo de otro fraude procesal". Ahora bien, de los propios términos de la ley, en cuanto hace depender la calificación de la circunstancia de que la estafa "se realice" de este modo particular, se desprende que la tipicidad general de la estafa procesal viene presupuesta conforme a las reglas generales y que la consagración legal sólo ha sido necesaria para los efectos de modificar la pena. En la actualidad la doctrina está conteste en atribuirle la calificación tanto a los casos en que el juez o funcionario es inducido mediante engaño por una de las partes a una decisión perjudicial para la contraparte, como también "cuando media colusión entre las partes, es decir, cuando las partes se ponen de acuerdo

${ }^{53}$ Véase al respecto, si bien no se refiere específicamente a la estafa en triángulo, Jakobs, G., "Rechtsentzug als Vermögensdelikt", en Sieber, U. et al. (Hrsg.), Strafrecht und Wirtschaftsstrafrecht. Festschrift für Klaus Tiedemann, Heymanns, Köln etc., 2008, p. 649 y ss. (hay versión castellana: "La privación de un derecho como delito patrimonial" [trad. Pastor], en InDret 4/2008).

${ }^{54}$ Debe distinguirse de la situación en que se engaña a la contraparte en el procedimiento, en virtud de la cual ésta realiza una disposición patrimonial perjudicial (allanamiento, desistimiento, transacción, etc.) que el tribunal u órgano, eventualmente, sólo sanciona. En estos casos se suele hablar de "estafa en el proceso" (así, por ejemplo, Seier, J., "Prozeßbetrug durch Rechts- und ungenügende Tatsachenbehauptungen”, en $Z S t W, 102,1990$, p. 564 con nota 2) o de "estafa procesal impropia" (así, por ejemplo, Choclán Montalvo, El delito de estafa, p. 314).

55 Entre otros Ferrer Sama, A., "Estafa procesal”, en ADPCP 1966, p. 5 y ss.; Cerezo Mir, J., "La estafa procesal", en ADPCP 1966, 179 y ss. (este artículo se encuentra ahora también en Cerezo Mir, J., Temas fundamentales del Derecho penal, T. I, Rubinzal-Culzoni, Buenos Aires, 2001, p. 307 y ss.); Torío López, Á., "Acción y resultado típico en la estafa procesal”, en AA. VV., Estudios penales. Libro Homenaje al Prof. J. Antón Oneca, Ediciones Universidad de Salamanca, Salamanca, 1982, p. 877 y ss., todos con referencias jurisprudenciales.

${ }^{56}$ Dicho reconocimiento se había verificado ya con anterioridad mediante la modificación del art. 529 del anterior Código, debida a la Ley de reforma parcial y urgente de 1983. 
para engañar al Juez en perjuicio de tercero" 57 , comprensión que goza de amplio respaldo en la jurisprudencia ${ }^{58}$.

En el caso del derecho alemán (Prozeßbetrug) la cuestión es también completamente pacífica, tanto en la doctrina científica como en la jurisprudencia ${ }^{59}$.

Hasta donde se alcanza a ver, el único ordenamiento europeo de cierta influencia entre nosotros en que mayoritariamente se rechaza la posibilidad de una estafa procesal es el italiano (truffa processuale). Fundamentalmente se objeta que la ubicación sistemática de la figura de estafa (art. 640 CP) en el ámbito de los delitos patrimoniales se opondría a su comprensión como un posible delito contra la administración de justicia, máxime si en el contexto de estos últimos existe una figura genérica de "fraude procesal" (art. 374 $\mathrm{CP}$ ). Asimismo se hace valer que faltaría una genuina "disposición patrimonial" por parte del juez o funcionario engañado, atendido el carácter público y no privado de las decisiones judiciales ${ }^{60}$. Sobre la refutación de estas razones se volverá luego.

En el caso del derecho chileno la doctrina ampliamente dominante no ve tampoco mayores dificultades a la hora de apreciar una estafa procesal subsumible en los tipos de estafa previstos en nuestro Código penal ${ }^{61}$. No obstante, debe reconocerse una cierta reticencia en nuestra práctica judicial al respecto ${ }^{62}$, reticencia que, sin embargo, además de no explicitar sus términos parece girar, como se verá, más en torno al reconocimiento formal de la figura que a la solución de los casos prácticos, de modo que difícilmente puede hablarse de una jurisprudencia contraria. Con todo, su existencia hace conveniente una revisión de las razones a favor y en contra del reconocimiento de la estafa procesal.

Una primera posible objeción intuitiva contra la estafa procesal, aun antes de la verificación de los requisitos propios de la estafa, podría consistir en que las conductas engañosas de las partes en un proceso atentan en primera línea contra la administración de justicia, de modo que debería verse configurado un delito contra dicho bien jurídico

57 Bajo Fernández, Los delitos de estafa, p. 112, énfasis en el original; en el mismo sentido ya Valle Muñiz, El delito de estafa, p. 219.

58 Por sólo mencionar una relativamente reciente, sentencia del TS de 4 de marzo de 1997.

${ }^{59}$ Así, entre muchos, Lackner, $L K \S 263$ marg. 110, 305 y ss.; Tiedemann, $L K \S 263$ marg. 113, 117; Cramer, P., Perron, W., “\$ 263”, en Schönke / Schröder. StGB-Kommentar, 27. Aufl., Beck, München, 2006, marg. 69 y ss.; Kindhäuser, $N K \S 263$ marg. 209 y ss., todos con abundantes referencias a la jurisprudencia.

${ }^{60} \mathrm{Al}$ respecto Dolcini, E., Marinucci, G., Codice penale commentato. Parte speciale, $2^{\mathrm{a}}$ edizione, IPSOA, Assago (Milano), 2006, Art. 640 marg. 33; Fiandaca, G., Musco, E., Diritto penale. Parte speciale, Vol. II, T. II, $3^{a}$ edizione, Zanichelli, Bologna, 2002, p. 184 y s.; Pedrazzi, C., Inganno ed errore nei delitti contro il patrimonio, Giuffrè, Milano, 1955, p. 108; Maggini, A., La truffa, CEDAM, Padova, 1988, p. 68 y ss.; Fanelli, A., La truffa, Giuffrè, Milano, 1998, p. 277 y ss.; Lucarelli, U., La truffa, CEDAM, Padova, 2002, p. 372 y ss. Es la posición claramente dominante también en la jurisprudencia.

${ }^{61}$ Así Etcheberry, T. III, p. 398; Hernández, “Aproximación”, p. 156 y s.; Politoff, Matus, Ramírez, $P E$, p. 421 y ss.; y especialmente Grisolía, "La estafa procesal”, p. 417 y ss. Reticente sólo Yubero, J., El engaño en el delito de estafa, ConoSur, Santiago, 1993, p. 57 y ss., pues Piña, Fraude de seguros, pp. 45 y s., 77 , sólo duda de la consistencia conceptual de la figura.

${ }^{62}$ Un panorama en Etcheberry, A., El derecho penal en la jurisprudencia, $2^{a}$ edición, Editorial Jurídica de Chile, Santiago, 1987, T. III, p. 22 y ss. 
-concretamente el delito de presentación de pruebas falsas previsto en el art. 207 CP, supuesto que en el caso concreto se dieran sus requisitos específicos- y no una estafa.

Al respecto cabe replicar, sin embargo, que sólo la primera parte del argumento es correcta, sin que de ello se siga forzosamente de modo alguno la conclusión final. En efecto, no puede desconocerse que el despliegue de una conducta engañosa en el desarrollo de un procedimiento judicial perturba seriamente el funcionamiento del sistema de justicia y por cierto puede llegar a configurar en concreto alguno de los delitos especialmente previstos por la ley para hacer frente a dicha perturbación. Al mismo tiempo, sin embargo, cuando la conducta tiene efectos perjudiciales en el patrimonio de una de las partes o de un tercero, tampoco puede desconocerse que la sola aplicación de los tipos contra la administración de justicia, que no se hacen cargo de este aspecto patrimonial individual, no está en condiciones de expresar debidamente y de responder al completo contenido de injusto del caso concreto $^{63}$, lo que sólo se logra si se traen a colación todos los tipos que recién en su conjunto abordan todas y cada una de las facetas lesivas del caso ${ }^{64}$, de modo que se está necesariamente ante un genuino concurso ideal de delitos (puede discutirse, aunque sin consecuencias, si no es un concurso medial) y no de un simple concurso aparente de leyes penales. Para decirlo en los términos del art. 75 $\mathrm{CP}$, se trataría de un caso en que un solo hecho constituye dos o más delitos (o en que uno es el medio necesario para cometer el otro): un delito contra la administración de justicia (eventual presentación de pruebas falsas) en concurso con un delito contra el patrimonio individual de una parte o de un tercero (estafa) ${ }^{65}$.

Debe hacerse notar, además, que en Chile no existe un tipo genérico de "fraude procesal" como el contenido en el mencionado art. 374 del Código italiano y que ciertamente le da más peso a la tesis de la regulación exhaustiva y excluyente ${ }^{66}$, sin perjuicio de que aun en ese contexto la consideración de la lesión al patrimonio individual debería dar lugar al reconocimiento del concurso ideal (o medial) ${ }^{67}$.

Lo verdaderamente decisivo entonces debe ser -con total prescindencia de si en la especie se verifican, además, los requisitos del art. 207 CP- si la figura de la estafa procesal cumple en efecto con todos los requisitos de la estafa.

Hasta aquí sólo se ha tematizado la exigencia de disposición patrimonial. Como se ha dicho, en la medida en que el juez y algunos funcionarios judiciales poseen facultades para adoptar decisiones que por mandato legal surten efecto sobre el patrimonio de las personas $-\mathrm{y}$ conforme al concepto amplio de disposición patrimonial dominante

${ }^{63}$ Sin contar con que desde un punto de vista procesal la sola consideración del delito contra la administración de justicia -delito contra un bien jurídico institucional- priva al perjudicado del derecho a intervenir en el procedimiento como querellante o aun como simple víctima (arts. 109 y $111 \mathrm{CPP}$ ).

${ }^{64}$ Es lo que en doctrina se conoce como "función de clarificación" (Klarstellungsfunktion) del concurso ideal de delitos. Al respecto, por todos, Roxin, C., Strafrecht, AT II, Beck, München, 2003, § 33 marg. 109.

${ }^{65}$ Ferrer Sama, "Estafa procesal", p. 9; Cerezo Mir, "La estafa procesal”, p. 181 y s.; Torío López, “Acción y resultado típico", p. 879.

${ }^{66}$ Lo destacaba también en relación con la ley española Ferrer Sama, "Estafa procesal", p. 9 y s.

${ }^{67}$ Así también Cerezo Mir, "La estafa procesal”, p. 182. 
también en Chile ${ }^{68}$ - no cabe dudar a la hora de atribuirle a dichas decisiones el carácter de disposición típica en los términos del delito de estafa ${ }^{69}$. Contra el planteamiento de la jurisprudencia italiana, el carácter público de la decisión judicial indudablemente le agrega notas excepcionales a la disposición patrimonial, no requeridas por el tipo de estafa, pero en caso alguno le resta ese carácter, en cuanto efectivamente afecta el patrimonio de las partes o de terceros. Se reconoce ampliamente que la vinculación jurídica entre la decisión judicial y el patrimonio no sólo de las partes sino también de terceros ajenos al procedimiento se encuentra suficientemente fundada en el imperio de las resoluciones judiciales, que, a despecho del principio general del efecto relativo de las mismas, puede afectar en concreto y de modo relevante a terceros, al menos en la forma de una apariencia jurídica con efectos que no son nada de aparentes, sino muy reales ${ }^{70}$.

Dicho esto, a continuación se procederá a la verificación en estos supuestos de los restantes requisitos de la estafa, a saber el engaño, el error y el carácter perjudicial de la disposición.

\section{Ejercicio de acciones legales infundadas, alegaciones falsas y engaño}

Una objeción importante contra la posibilidad de una estafa procesal consiste en sostener que la simple interposición de acciones judiciales, por infundadas que éstas sean -más aún: por conscientemente falsos que sean sus fundamentos-, no puede constituir engaño típico en los términos de la estafa, ya que, en palabras de Etcheberry, "el pleito se fallará según el mérito de las pruebas y conforme a derecho, y la contraparte tendrá oportunidad de refutar las pretensiones del demandante, objetar su prueba y rendir la propia"71. O como sostiene Yubero: "A menudo, las pretensiones de las partes son aventuradas o excesivas (no sin sabiduría, el adagio popular que [sic] 'en pedir no hay engaño'); empero, cualquiera que sea la entidad de estas pretensiones, carecen de significado en cuanto se refiere a la configuración de la estafa. La temeridad de los litigantes no está sujeta a más sanción jurídica que la condenación en costas”. A lo que agrega: "Vale tener en vista, por último, que el proceso civil no es sino una controversia en que las partes aducen sus alegaciones y rinden las pruebas conducentes a la demostración de su derecho; y vale la pena tenerlo en vista porque de ello puede deducirse que si el juez yerra, más será por incumplimiento de su deber o por negligencia del vencido que por astuta conducta de un embaucador" 72 .

${ }^{68}$ Hernández, “Aproximación”, p. 170; Etcheberry, T. III, p. 398 y s.; Politoff, Matus, Ramírez, PE, p. 433 y s.; específicamente para la estafa procesal Grisolía, "La estafa procesal”, p. 421.

${ }^{69}$ En España Ferrer Sama, “Estafa procesal”, p. 8; Cerezo Mir, "La estafa procesal”, p. 193 y s. En Chile Grisolía, "La estafa procesal”, p. 421. En Alemania, por todos, Lackner, LK § 263 marg. 310.

70 Tiedemann, $L K \S 263$ marg. 117; Lackner, $L K \S 263$ marg. 304 y ss.

${ }^{71}$ Etcheberry, El derecho penal en la jurisprudencia, T. III, p. 22.

${ }^{72}$ Yubero, El engaño, p. 59. 
Porque si bien la ausencia de consagración expresa en el derecho chileno de deberes procesales de veracidad extraprobatorios ${ }^{73}$ no parece haber sido obstáculo para que se afirmen tales deberes como emanación del principio de la buena fe procesal ${ }^{74}$, lo cierto es que es conceptualmente dudoso no sólo que dicho principio general pueda por sí solo soportar la justificación de deberes específicos de ese tipo ${ }^{75}$, sino además que las alegaciones conscientemente falsas puedan considerarse relevantes a título de engaño típico de la estafa cuando el contexto institucional del proceso implica que las resoluciones judiciales se deben fundar en la prueba y no en tales alegaciones ${ }^{76}$.

Al respecto es ilustrativa la experiencia en Alemania, donde hasta la introducción en 1933 de los deberes de veracidad de las partes en materia civil ( $\$ 138$ ZPO) sólo se admitía en general la presencia de una estafa procesal tratándose de juicios simulados o de la presentación de pruebas falsas, en tanto que las simples alegaciones falsas -al margen de la discusión sobre si podían constituir engaño típico- no podían dar lugar a una estafa por consideraciones estrictamente causales: en la medida en que el juez no podía darles crédito si no estaban debidamente probadas o reconocidas por la contraparte, no podían provocar el error típico; si, no obstante y con infracción de su deber, el juez las acogía con independencia de la prueba rendida, entonces la causa del error era la infracción del deber y no las alegaciones de la parte ${ }^{77}$. Si el razonamiento era coherente

73 A diferencia de lo que ocurre especialmente en Alemania, donde el $\S 138$ ZPO impone de modo inequívoco verdaderos deberes de veracidad y exhaustividad, con consecuencias muy significativas en materia de estafa, pues la opinión dominante afirma a partir de dichos deberes la tipicidad de las simples alegaciones falsas o incompletas. En España, si bien la construcción de deberes de ese tipo debe hacerse a partir del principio de la buena fe procesal (art. 11 LOPJ, art. 247 LEC), el incumplimiento de ese "deber de buena fe” también ha servido para apreciar un engaño típico, aunque al parecer en términos más restrictivos. Cfr. Choclán Montalvo, El delito de estafa, p. 317 y s.

${ }^{74} \mathrm{Al}$ respecto, si bien no son en absoluto enfáticos en afirmar genuinos deberes de veracidad, Romero, A., "El principio de la buena fe procesal y su desarrollo en la jurisprudencia, a la luz de la doctrina de los actos propios", en Revista Chilena de Derecho, Vol. 30, 2003, p. 169 y s.; Carretta, F., "Deberes procesales de las partes en el proceso civil chileno: referencia a la buena fe procesal y al deber de coherencia", en Revista de Derecho, Universidad Austral de Chile, Vol. XXI N 1, 2008, p. 119 y ss.

75 Véanse las incisivas razones de Hunter, I., "No hay buena fe sin interés: la buena fe procesal y los deberes de veracidad, completitud y colaboración”, en Revista de Derecho, Universidad Austral de Chile, Vol. XXI No 2, 2008, pp. 156 y s., 164 y ss. Esto con independencia del carácter más bien débil de la idea de verdad que subyace al rol de los abogados, especialmente bajo un modelo que los concibe como defensores de los intereses del cliente antes que como auxiliares de la administración de justicia, modelo cuya ubicuidad es evidente, al margen de que sea discutible su posición dominante en todos los contextos procesales en nuestro país. Al respecto Coloma, R., "Vamos a contar mentiras, tralará..., o de límites a los dichos de los abogados”, en Revista de Derecho, Universidad Austral de Chile, Vol. XIX N 2, 2006, p. 42 y ss.

${ }^{76}$ Nótese que de ningún modo se está sugiriendo que la "simple mentira" no pueda ser engaño típico, sino solamente que la mentira típica debe ser relevante en términos de poder servir de base para la disposición patrimonial, en este caso para la resolución judicial. Por así decirlo, en estos casos no se trata de la necesaria "relevancia negocial", sino de una necesaria relevancia institucional.

77 Jänicke. H., Gerichtliche Entscheidungen als Vermögensverfügung im Sinne des Betrugstatbestandes, Duncker \& Humblot, Berlin, 2001, p. 121 y ss. 
desde un punto de vista causal ${ }^{78}$ es algo que puede quedar sin contestar si, como ocurre en la actualidad, se asume que el punto a resolver no es el de la causa de un posible error, sino el de la relevancia de las afirmaciones falsas ${ }^{79}$, entendiendo por relevantes aquellas que se dan en un contexto y versan sobre objetos que imponen un deber de veracidad. En la época no parecía ser el caso de las simples alegaciones falsas en Alemania, como tampoco parece serlo hoy en Chile.

Como fuera, al menos parece innegable que la objeción sólo se sostiene, al margen de lo fundadas o justas que puedan ser las pretensiones, en presencia de un procedimiento real en el que se presenten pruebas auténticas, pero no en uno en que tales condiciones simplemente se simulan ante el juez. En estos casos ya se ha abandonado largamente el plano de la simple interposición de una acción o de una simple alegación (un "simple pedir" que como tal no puede implicar engaño) y se entra de lleno en los dominios del engaño, típico también en los términos de la estafa.

Por lo demás, así lo reconoce claramente el derecho vigente, tanto a través del mencionado tipo penal de presentación de pruebas falsas, como de otros remedios para hacer frente a conductas fraudulentas en el proceso, como es el caso paradigmático de la revisión de sentencias firmes (art. 810 y ss. CPC, art. 473 y ss. CPP). Mientras que para los casos normales de error judicial, eventualmente motivados también por la astucia o destreza de los litigantes, la ley sólo otorga los recursos de apelación y de casación o nulidad, que tienen su límite infranqueable en la ejecutoria de la resolución, frente a conductas abiertamente fraudulentas -que son las que interesan para este trabajo- la ley está dispuesta incluso a pasar por sobre la autoridad de cosa juzgada de las mismas, a través del recurso o acción de revisión. En este contexto interesan especialmente los tres primeros supuestos del art. 810 CPC, conforme al cual la Corte Suprema puede rever una sentencia firme:

“ $1^{\circ}$. Si se ha fundado en documentos declarados falsos por sentencia ejecutoria, dictada con posterioridad a la sentencia que se trata de rever;

$2^{\circ}$. Si pronunciada en virtud de pruebas de testigos, han sido éstos condenados por falso testimonio dado especialmente en las declaraciones que sirvieron de único fundamento a la sentencia;

$3^{\circ}$. Si la sentencia firme se ha ganado injustamente en virtud de cohecho, violencia $u$ otra maquinación fraudulenta, cuya existencia haya sido declarada por sentencia de término".

${ }^{78}$ Lo rebate Jänicke, Gerichtliche Entscheidungen, p. 153, a la luz del amplio predominio de la equivalencia de las condiciones en la jurisprudencia del Tribunal Imperial. De ahí que, a su juicio, la introducción de los deberes de veracidad en rigor fue el pretexto para un cambio jurisprudencial condicionado por el nuevo ambiente político a partir de 1933 (p. 155 y ss.). Con independencia de la plausibilidad de la tesis, desde una perspectiva actual de la dogmática de la estafa, sin embargo, no parece que ese cambio legislativo pueda considerarse neutral o intrascendente.

${ }^{79}$ En términos similares, de imputación objetiva (imputación al ámbito de competencia del juez) Seier, "Prozeßbetrug", pp. 566, 572 y ss. 
Como se ve, la ley distingue nítidamente entre la relativa incertidumbre que es propia de cualquier proceso judicial y la actividad fraudulenta que incide en él, la que, de modo explícito ( $\mathrm{N}^{\mathrm{o}}$ 3), va más allá del uso de pruebas falsas. Es ésta actividad fraudulenta la que puede constituir engaño típico en los términos de la estafa. Específicamente, por el especial despliegue que representa la simulación de pruebas o de un procedimiento falso, en principio el tipo calificado del art. $468 \mathrm{CP}^{80}$, pues, en palabras de Grisolía: “(q)uienes inventan un pleito para engañar al juez de modo que éste libre una sentencia injusta apta para perjudicar pecuniariamente a un tercero, despliegan una comedia procesal movidos por un afán de lucro: se atribuyen un crédito supuesto; aparentan la existencia del crédito que viene a ser el valor de la pretensión demandada -correlativamente el débito supuesto del demandado- y, en todo caso, demandar lo que no existe es un engaño semejante al descrito" 81 .

\section{Facultades regladas y error}

Desde luego no parece que pueda negarse a priori la posibilidad de engaño a un juez o funcionario (y su consecuente efecto de error en el mismo), a menos que se sostuviera que el ejercicio de la función jurisdiccional los vuelve seres a tal punto diferentes del resto que no pueden ser inducidos a error. Como es obvio, sin embargo, semejante representación no resiste análisis ${ }^{82}$.

Lo que en rigor parece subyacer a la relativa reticencia judicial en nuestro país es el malentendido consistente en ver en la afirmación de una estafa procesal la atribución de un cierto grado de responsabilidad al juez en la conducta fraudulenta, en circunstancias que, por definición, el engañado ha sido instrumentalizado y, por ende, no pueda ser hecho responsable ${ }^{83}$. En algunos casos nuestra jurisprudencia ha sorteado este prejuicio infundado mediante la ficción de que la persona engañada sería el demandado o el tercero perjudicado y no el tribunal. Tal parece ser el caso, por ejemplo, en una sentencia de la Corte Suprema que rechaza el recurso del condenado que había obtenido mediante engaño en procedimiento laboral el embargo y la subasta de una cosecha de papas sembradas por terceros en un predio cercano a aquél en que él había sembrado (también papas) para el demandado; el engaño habría consistido en hacer creer que la cosecha embargada correspondía a las papas que él había sembrado, en circunstancias

${ }^{80}$ Si bien se trata de una interpretación más que dudosa, se acoge aquí la opinión ampliamente mayoritaria en Chile en cuanto a que el art. 468 CP recoge hipótesis elaboradas de engaño (ardid o mise en scène), en tanto que el residual art. $473 \mathrm{CP}$ se haría cargo de los engaños más sencillos. Al respecto fundamental Etcheberry, T. III, p. 407.

${ }^{81}$ Grisolía, "La estafa procesal”, p. 419 y s., énfasis en el original. Adhieren Politoff, Matus, Ramírez, $P E$, p. 423.

82 Cerezo Mir, "La estafa procesal”, p. 191; Torío López, "Acción y resultado típico”, p. 878 y s.; Choclán Montalvo, El delito de estafa, p. 315; Grisolía, "La estafa procesal”, p. 417 y s.

83 Cerezo Mir, "La estafa procesal”, p. 191. 
que ésas ya habían sido cosechadas con anterioridad ${ }^{84}$. Como se ve, el fallo es un claro reconocimiento de la estafa procesal, reconocimiento que, sin embargo, incurre en el defecto innecesario de radicar el error en un sujeto distinto del verdadero engañado, que a todas luces fue el tribunal que ordenó la subasta y no el dueño de la cosecha que sufrió el perjuicio ${ }^{85}$.

Ahora bien, superadas estas objeciones totalmente infundadas, hay que hacerse cargo de otras que sí son de consideración. Probablemente el requisito que más dudas provoca en el tratamiento de la estafa procesal en los casos concretos sea el error típico, entendido éste como una representación falsa de los hechos por parte del juez o funcionario.

En único punto respecto del cual parece existir amplio acuerdo es en cuanto a la procedencia de afirmar el error del juez en los casos de procesos simulados o aparentes en los que simplemente se finge una controversia inexistente con el único propósito de perjudicar a un tercero ajeno al pleito ${ }^{86}$. En tales casos -que, en efecto, constituyen la hipótesis más pacífica de reconocimiento de la estafa procesal ${ }^{87}$ - sencillamente no existe contraparte real interesada en demostrar la falsedad de lo sostenido por la otra, sino que más bien coadyuva al engaño que sufre el tribunal, que asume que está conociendo de un litigio real. Nótese que no se trata de atribuirle al juez ninguna representación sobre la justicia de las pretensiones de las partes, sino simplemente de asumir que éste no puede sino representarse que realmente está tratando con "partes" que someten a su decisión una controversia verdadera. En la medida en que dicha representación básica no corresponde a la realidad puede afirmarse sin más el error típico ${ }^{88}$.

En lo demás, las dudas dicen relación con las particularidades institucionales de las decisiones judiciales, derivadas de la forma en que están concebidas y reguladas tanto la iniciativa probatoria como el onus probandi y la convicción del tribunal en cada contexto normativo particular ${ }^{89}$.

Así, en un contexto de estricta sujeción al principio dispositivo y a un sistema de prueba tasada o legal ${ }^{90}$ es perfectamente posible que la decisión del juez no se base en

${ }^{84}$ RDJ, T. XLVIII (1951), $2^{\mathrm{a}}$ parte, sección $4^{\mathrm{a}}$, p. 286 (Sánchez contra Llacanleo y otro), una síntesis en Etcheberry, El derecho penal en la jurisprudencia, T. III, p. 16 y s.

${ }^{85}$ Nótese que Etcheberry, El derecho penal en la jurisprudencia, T. III, p. 16 y s., no trata el caso bajo el concepto de estafa procesal.

${ }^{86}$ Cerezo Mir, "La estafa procesal”, p. 192; Grisolía, "La estafa procesal”, p. 418 y s. Posición unánime desde antiguo en la jurisprudencia alemana, al punto que el caso suele no mencionarse siquiera en el contexto de la discusión sobre el error en la estafa procesal; al respecto véanse las abundantes referencias jurisprudenciales en Jänicke, Gerichtliche Entscheidungen, p. 141 y s.

${ }^{87}$ Como destaca Cerezo Mir, "La estafa procesal”, p. 189 con nota 43, incluso los escépticos del concepto reconocen en este tipo de casos la concurrencia de los requisitos de la estafa.

${ }^{88}$ Debe reconocerse que el argumento, además de ser sospechoso de elevar a la categoría de error una simple forma de ignorantia facti, esto es, una vaga impresión de estar "todo en orden”, que por regla general no se considera suficiente, reemplaza la constatación de un estado psíquico por una atribución normativa, lo que, sin embargo, como se verá todavía en este apartado, se considera correcto y necesario.

89 Al respecto Hernández, “Aproximación”, p. 157.

${ }^{90}$ Como se sabe, fuera del proceso penal la regla general en el derecho procesal chileno sigue siendo precisamente el predominio del principio dispositivo (sólo morigerado por la previsión de "medidas para 
ninguna convicción personal -que el juez simplemente no se haya hecho ninguna representación- respecto de cómo ocurrieron en la realidad los hechos sobre los cuales se resuelve. Más aún, es incluso posible que, dadas las condiciones legales, deba fallar contra su propia convicción. Obviamente es difícil que en casos como éstos se pueda hablar de un error típico en los términos de la estafa, al menos en la forma en que éste se entiende tradicionalmente ${ }^{91}$.

La situación es en principio diferente en los ámbitos en que rige un sistema de libre valoración de la prueba con deber de fundamentación (sana crítica), en los cuales, por definición, se requiere una convicción fundada del juzgador, de modo que el elemento error en caso de presentación de pruebas falsas no debería acarrear mayores dificultades. Es lo que rige actualmente en materia laboral (art. 456 Código del Trabajo) o en materia de familia (art. 32 Ley $\left.\mathrm{N}^{\circ} 19.968\right)^{92}$, entre otras ${ }^{93}$. Pero también en este contexto surgen problemas en los casos de non liquet, en los que el juez que no ha adquirido convicción ni en un sentido ni en otro tiene que resolver formalmente -sólo en virtud del mandato legal-contra aquél sobre quien pesaba la carga de la prueba.

En todo caso, los problemas principales en este contexto se dan a propósito de procedimientos especiales altamente formalizados en que puede resolverse sin contradictorio ni especial convicción del juez, como es el caso de ciertas variantes de los procedimientos monitorios y de los procedimientos en rebeldía conocidas en el derecho comparado ${ }^{94}$, y en general en cualquier contexto en que el juez o funcionario no tenga el deber -y más aún: no tenga siquiera la facultad- de enjuiciar realmente el objeto del procedimiento. En el derecho chileno, tal es el caso, por ejemplo, del reconocimiento de firma en instrumento privado que no sea letra de cambio ni pagaré95 como preparación de la vía

mejor resolver" conforme al art. 159 CPC) y el sistema de prueba tasada o legal consagrado en el Código Civil (v. gr. arts. 1700, 1702, 1704, 1706, 1713) y en el Código de Procedimiento Civil (v. gr. 383, 384 , 398, 399, 408, 427), al respecto sigue siendo válida la visión de Peñailillo, D., La prueba en materia sustantiva civil. Parte general, Editorial Jurídica de Chile, Santiago 1989, p. 23 y s.

${ }^{91} \mathrm{Al}$ respecto, en general, Lackner, $L K \S 263$ marg. 311 y ss.; Tiedemann, $L K \S 263$ marg. 85, 86, 90 y s.; Cramer, Perron, en Schönke / Schröder, § 263 marg. 70 y s. En España Cerezo Mir, "La estafa procesal”, p. 189 y ss.

92 En ambas materias se aprecia, además, una importante apertura al principio inquisitivo, como se desprende del art. 429 del Código del Trabajo y del inciso final del art. 29 de la Ley No 19.968.

${ }^{93} \mathrm{El}$ art. 15 del Anteproyecto de Código Procesal Civil consagra este sistema con carácter general.

${ }^{94}$ Un panorama general al respecto, si bien obviamente no orientado a los problemas de la estafa procesal, en Pérez Ragone, Á., "En torno al procedimiento monitorio desde el derecho procesal comparado europeo: caracterización, elementos esenciales y accidentes", en Revista de Derecho, Universidad Austral de Chile, Vol. XIX Nº 1, 2006, p. 205 y ss.; Orellana, F., Pérez Ragone, Á., "Radiografía de la rebeldía en el proceso civil: tópicos hacia una adecuada regulación en la nueva justicia civil”, en Ius et Praxis, Año 13 $\mathrm{N}^{\circ} 2,2007$, p. 13 y ss.

${ }^{95}$ Respecto de estos documentos la tacha de falsedad se tramita como incidente (art. 111 Ley No 18.092), el que, si se resuelve contra el tenedor en virtud de un error que la tacha mendaz provoca en el juez, daría lugar a un caso sencillo de estafa con total independencia de lo que se viene discutiendo en este apartado. No lo vio así, lamentablemente, la Corte Suprema en fallo de RDJ, T. LIV (1957), 2a parte, sección $4^{\mathrm{a}}, 194$ (Morand contra Palacios), obligando a la intervención legislativa (delito del art. 110 Ley N 18.092). 
ejecutiva conforme al art. $435 \mathrm{~N}^{\circ} 4$ CPC: si el deudor comparece y desconoce la firma termina la preparación y el acreedor se queda (en virtud de la resolución que lo declara) sin título ejecutivo, sin que pueda discutirse en el mismo procedimiento la autenticidad de la firma ${ }^{96}$. No parece serlo, en cambio, tratándose del nuevo procedimiento monitorio en materia laboral, que supone que el juez emita un juicio siquiera provisional sobre el fondo del asunto, en cuanto acoge inmediatamente las pretensiones del demandante sólo cuando las "estime fundadas", reservando el pronunciamiento para la audiencia de juicio de no existir antecedentes suficientes (art. 500 Código del Trabajo). O en el caso del Conservador de Bienes Raíces a quien se le solicita la inscripción de un título falsificado en perjuicio del legítimo poseedor inscrito ${ }^{97}$. Conforme al art. 13 del Reglamento de Registro Conservatorio de Bienes Raíces el conservador no puede rehusar ni retardar las inscripciones, pero "deberá, no obstante, negarse, si la inscripción es en algún sentido legalmente inadmisible”. Y si bien se tiende a interpretar esta última expresión con una menor amplitud que la que a primera vista pudiera atribuírsele, en la línea de reducirla a la verificación de requisitos formales ${ }^{98}$, al menos el ejemplo expreso de no ser auténtico el título debería bastar para considerar que en aquellos casos el conservador sólo puede inscribir en la convicción de tratarse de título auténtico.

Ahora bien, como se ve, esta caracterización de los distintos tipos de procedimientos sólo ilustra sobre los distintos grados o frecuencias con que se manifiesta un único problema, pues en todos los tipos de procedimiento es posible que en el caso concreto el juez o funcionario pueda y hasta deba resolver sin tener convicción respecto de la verdad de los hechos sometidos a su consideración o, incluso, que deba resolver contra su convicción pero obligado por las reglas que disciplinan la actividad judicial. La cuestión es siempre la misma: si en tales casos puede afirmarse el error típico.

En Alemania la clave para afirmar el error típico prácticamente en todas las situaciones ha sido la redefinición del objeto del mismo, que de la verdad de la versión de los hechos se traslada a la veracidad de quien la presenta, porque, se dice, el tribunal

\footnotetext{
${ }^{96}$ Cfr. Espinosa, R., Manual de procedimiento civil. El juicio ejecutivo, $11^{\text {a }}$ edición, Editorial Jurídica de Chile, Santiago, 2003, p. 39.

${ }^{97}$ Un buen ejemplo lo dan los hechos tenidos por probados en la sentencia del $4^{\circ}$ Tribunal Oral en lo Penal de Santiago, de 15 de noviembre de 2007 (RIT 115-2007): unos sujetos ajenos a una sociedad anónima de inversiones reducen a escritura pública supuestas actas de juntas de accionistas y de sesiones de directorio de dicha sociedad, conforme a las cuales - de modo por completo imaginario- uno de ellos es nombrado miembro del directorio y recibe poderes (que luego son supuestamente ratificados) para representar a la sociedad como director gerente, calidad en virtud de la cual le vende a otro de los sujetos dos inmuebles de propiedad de la sociedad, compraventas que luego son inscritas en el Conservador de Bienes Raíces. Con posterioridad se constituyeron hipotecas sobre los inmuebles. El tribunal no apreció la estafa en perjuicio de la sociedad, lamentablemente con el argumento impertinente de que no habría habido engaño para inducir a los representantes de la sociedad a disponer de sus bienes, porque el engañado que dispuso sobre los mismos, al inscribir el título apócrifo, fue el conservador. En la especie sólo se apreció estafa respecto de terceros que, en virtud de las hipotecas, otorgaron mutuos a los autores.

${ }^{98}$ Al respecto, por todos, Peñailillo, D., Los bienes. La propiedad y otros derechos reales, Editorial Jurídica de Chile, Santiago, 2006, p. 268 y s.
} 
no puede sino asumir, en virtud del ya mencionado deber de veracidad, que el peticionario no está sosteniendo conscientemente algo falso ${ }^{99}$. Es dudoso, sin embargo, que el mismo argumento se pueda emplear en el derecho chileno, no porque la representación no pueda ser plausible, sino porque en ausencia de deber de veracidad el objeto del error relevante debe ser necesariamente la verdad de lo que se presenta al tribunal, objeto respecto del cual en los casos en cuestión simplemente puede no existir representación alguna. Todo parece indicar que una aplicación coherente del concepto de error como falsa representación de la realidad debe conducir a negar la existencia de un error típico al menos en algunos de estos casos, si no en todos ${ }^{100}$.

Sólo parece posible arribar a una conclusión diferente por la vía de la normativización del concepto de error, en sintonía con una tendencia general en el discurso dogmático, que alcanza también a los elementos de la estafa. Dicha normativización resulta correcta y necesaria en el entendido de que por esta vía se enfatiza la función del concepto por sobre el fenómeno psíquico asociado, y en ningún caso la simple prescindencia de dicha función ${ }^{101}$.

En el contexto de un delito de autolesión como es la estafa, caracterizado porque el perjuicio patrimonial no lo ocasiona el autor sino la propia víctima (o quien actúa por ella) a través de una disposición patrimonial, esto es, a través de una manifestación de voluntad con efectos patrimoniales, el elemento error es lo que justifica que sea el autor el que debe responder por un hecho voluntario que en principio sólo es de incumbencia y responsabilidad de quien lo realiza. En efecto, si no obstante la voluntariedad de la disposición perjudicial ésta es imputada al autor como su hecho en vez de ser tratada como una liberalidad más o menos torpe del disponente, es única y exclusivamente porque el autor ha instrumentalizado a la víctima (o a quien actúa por ella) a través de un medio típicamente relevante como es el engaño ${ }^{102}$. Lo central es, en consecuencia, que se pueda hablar con sentido de una instrumentalización de la víctima (o de quien actúa por ella).

Esto es indudable cuando el disponente efectivamente incurre en error como hecho psíquico, es decir, cuando en virtud del engaño ha ignorado el verdadero sentido de su disposición. Pero también debería serlo, por equivalencia funcional, cuando con independencia de su representación se encuentra jurídicamente obligado a resolver en el sentido

${ }^{99}$ Paradigmático Krey, Hellmann, BT 2, § 11 marg. 421 y s.; también Kindhäuser, NK § 263 marg. 191 y s.

${ }^{100} \mathrm{Al}$ respecto, si bien la opinión mayoritaria y la jurisprudencia en Alemania afirman estafa en todos los casos, Tiedemann, $L K \S 263$ marg. 90; Lackner, $L K \S 263$ marg. 313 y s.; Giehring, H., "Prozeßbetrug im Versäumnis- und Mahnverfahren - zugleich ein Beitrag zur Auslegung des Irrtumsbegriffs in $\S 263$ StGB”, en $G A, 1973$, p. 6 y ss.

${ }^{101}$ Entre nosotros ha abogado recientemente por la prescindencia del error como exigencia de la estafa Balmaceda, G., El delito de estafa informática, Ediciones Jurídicas de Santiago, Santiago, 2009, pp. 221 y s., $327,351,362$ y s., 370 y ss.; y al menos ha considerado esa posibilidad, aunque sin abrazarla, Piña, Fraude de seguros, p. 77.

102 Por todos Kindhäuser, NK § 263 marg. 168. 
de la información presentada, esto es, cuando en virtud de una decisión legislativa o provista de imperio la sola presentación de la información tiene la fuerza de pasar por sobre el juicio y la convicción del disponente. Así, en el plano procesal, es razonable atribuir error (circunstancia de haber sido instrumentalizado) cuando en un contexto que permite (y asegura) el efectivo discernimiento judicial (procedimiento contradictorio, libre valoración motivada), no obstante, los medios de prueba falsos obligan a fallar conforme a una regla de clausura necesaria como es la carga de la prueba.

Pero lo mismo debe regir en los casos más extremos en que el sistema de antemano ha renunciado a toda forma de control judicial efectivo, y el tribunal u órgano sólo cumple una función de validación formal (que por algo en algunos ordenamientos se realiza, incluso, en forma automatizada) ${ }^{103}$. En estos casos, en la medida en que le está vedado verificar la corrección de la información, el ordenamiento jurídico ha dejado al disponente (y al titular del patrimonio en cuestión) a merced de aquélla que sea eventualmente falsa, esto es, ha asumido que en esa medida sea instrumentalizado, con lo cual al mismo tiempo ha creado un equivalente funcional del error que, coherentemente, debe valer tanto como aquél. Puede parecer contradictorio que se afirme un error precisamente ahí donde el ordenamiento ha suprimido los presupuestos mismos de una representación falsa y que, contra la regla, se afirme la tipicidad a título de estafa por el mero aprovechamiento de debilidades conscientemente asumidas del sistema. Sin embargo, este no es más que el correlato necesario, también en el ámbito patrimonial, de la decisión legislativa en orden a asegurar propiedades indispensables de cualquier procedimiento público, como es su capacidad resolutiva, o la expedición en ciertos procedimientos especiales. Junto con asumirse el riesgo de aprovechamiento abusivo derivado del logro de esos propósitos, no puede sino asumirse que la respuesta del sistema frente a la efectiva instrumentalización del mecanismo sea la misma que correspondería en cualquier otro contexto. Desde el punto de vista del titular del patrimonio en cuestión, a los riesgos a que su patrimonio se ve expuesto por razones institucionales, al menos no se suma una protección de inferior calidad.

En síntesis, en los ámbitos y en la medida en que el tribunal resuelve en base a convicción, la responsabilidad por la disposición perjudicial sólo recae sobre el autor si su engaño ha provocado una falsa representación de la realidad en el juez, en virtud de la cual resuelve; en los contextos y en la medida en que la ley restringe o excluye la decisión judicial en base a convicción, esa responsabilidad fluye directamente del hecho de haber provocado con la conducta engañosa la disposición perjudicial.

\section{Efecto de las resoluciones y perjuicio patrimonial}

En cuanto al carácter perjudicial de la decisión obtenida mediante engaño en el ámbito patrimonial, éste es más o menos evidente desde la perspectiva de cualquier concepto de patrimonio orientado a la realidad económica de las cosas y no exclusivamente

103 Así Pawlik, Das unerlaubte Verbalten, p. 244 y s. 
formal, lo que constituye una característica común a todos los conceptos de patrimonio y de perjuicio actualmente en discusión en el debate tanto chileno como comparado. Es el caso de las concepciones mixtas o económico-jurídicas dominantes (como lo sería también, por cierto, el de un concepto estrictamente económico), incluyendo los que podría denominarse conceptos "neojurídicos", pero también, si bien desde otro punto de partida, el de las concepciones personales ${ }^{104}$.

En efecto, conforme a cualquier concepto orientado a la realidad económica la afirmación de un perjuicio dependerá de que la decisión obtenida mediante engaño disminuya el valor económico del patrimonio sobre el cual tiene efectos relevantes dicha decisión. $\mathrm{Y}$ esto parece indiscutible no sólo en los casos obvios en que se pierde definitivamente un bien o derecho o se grava definitivamente el patrimonio, sino ya en cualquier caso en que la decisión judicial implique una traba al pleno ejercicio de los derechos que se tienen sobre determinadas cosas o el deterioro de un crédito.

Considérese, por ejemplo, el impacto económico que tiene sobre el patrimonio del dueño de un objeto que éste sea embargado o incautado o que se reconozca judicialmente sobre él, siquiera provisionalmente, un derecho ajeno aparente. Resulta evidente que el carácter litigioso del objeto incide negativamente en la valoración económica del patrimonio de su titular, con total prescindencia de que se trate de situaciones imputables a decisiones que, en cuanto erróneas, deberían poder ser revertidas ejercitando judicialmente las acciones legales correspondientes. Sostener lo contrario equivale a decir que el estafado -sea que haya sido víctima de una estafa directa o triangularnunca sufre perjuicio mientras pueda entablar acciones judiciales, dependiendo del resultado de las mismas la calificación jurídica de los hechos. Del mismo modo, sólo a partir de un formalismo extremo podría sostenerse que no se perjudica el patrimonio del acreedor cuando se configuran fraudulentamente privilegios falsos que van desplazando su crédito. Como se sabe -y se expresa nítidamente en la contabilidad de cualquier patrimonio- los créditos pierden valor económico en la medida en que su satisfacción se hace más dudosa, al punto de no valer nada -y ser "castigados"- cuando se tornan "incobrables".

Ante ejemplos como éstos se aprecia con radical nitidez la diferencia entre un concepto de patrimonio atento a la realidad económica y otro meramente formal. Sólo a partir de un concepto del segundo tipo podría negarse la manifiesta pérdida de valor que sufre el titular de un derecho (un bien, un crédito), con el consuelo pueril de que "tiene la razón”, en circunstancias que desde el punto de vista de las valoraciones económicas no basta con tener el derecho, sino que además se requiere poder ejercerlo plenamente, que es precisamente lo que no ocurre cuando en un Estado de Derecho un tribunal ha resuelto en sentido contrario.

Por último, íntimamente relacionada con los conceptos de patrimonio y perjuicio se encuentra la determinación del momento consumativo de la estafa procesal. Para los efectos

${ }^{104}$ Una síntesis de los conceptos de patrimonio y perjuicio puede verse en Hernández, “Aproximación”, p. 171 y ss.; Cueto, G., El delito de apropiación indebida. Administración desleal, Ediciones Jurídicas de Santiago, Santiago, 2005, p. 223 y ss.; Schlack, "El concepto de patrimonio", p. 261 y ss. 
de esta caracterización general de la estafa procesal baste con señalar que la discusión al respecto gira en torno a si es posible hablar ya de estafa consumada antes de que se dicte la resolución obtenida mediante engaño, haciendo valer que ya el peligro concreto de que se dicte la misma -configurado mediante la existencia del procedimiento y la presentación de una situación favorable a una resolución en un determinado sentidoafecta perjudicialmente el patrimonio de la contraparte o del tercero ${ }^{105}$. Más allá de este punto discutido, existe amplio consenso en cuanto a que la estafa debe considerarse consumada al menos con el pronunciamiento de la resolución obtenida mediante engaño, en cuando ésta esté en condiciones de ser ejecutada (con lo cual no es necesario que se encuentre a firme $)^{106}$. Con eso ya se considera irrogado el perjuicio típico exigido por la estafa. Por lo mismo, no puede caber duda alguna al respecto en los casos en que, además, se ha ejecutado efectivamente la resolución ${ }^{107}$.

\section{BIBLIOGRAFÍA}

Amelung, K., "Irrtum und Zweifel des Getäuschten beim Betrug", en GA, 1977, p. 1 y ss.

Bacigalupo, E., Falsedad documental, estafa y administración desleal, Marcial Pons, MadridBarcelona-Buenos Aires, 2007.

Backmann, L., Die Abgrenzung des Betrugs von Diebstabl und Unterschlagung, Heymanns, Köln etc., 1974.

Bajo Fernández, M., Los delitos de estafa en el Código penal, Editorial Universitaria Ramón Areces, Madrid, 2004.

Balmaceda, G., Peller, G. F., “Análisis dogmático del concepto de 'perjuicio’ en el delito de estafa (especial referencia al concepto de 'perjuicio en forma de peligro')”, en Revista de Estudios de la Justicia, $\mathrm{N}^{\circ} 7,2006$, p. 185 y ss.

Balmaceda, G., El delito de estafa informática, Ediciones Jurídicas de Santiago, Santiago, 2009.

BASCUÑÁN, A., "Delito de estafa e intromisión fraudulenta en mercados regulados", minuta inédita, 2006.

Carretta, F., "Deberes procesales de las partes en el proceso civil chileno: referencia a la buena fe procesal y al deber de coherencia”, en Revista de Derecho, Universidad Austral de Chile, Vol. XXI N ${ }^{\circ} 1,2008$, p. 101 y ss.

Cerezo Mir, J., "La estafa procesal", en Anuario de Derecho Penal y Ciencias Penales, 1966, p. 179 y ss.

Choclán Montalvo, J. A., El delito de estafa, 2ª edición, Bosch, Barcelona, 2009.

105 Mediante aplicación del concepto de "puesta en peligro del patrimonio" equivalente o, mejor, constitutiva de perjuicio, ampliamente reconocida en la jurisprudencia alemana. Al respecto Hernández, “Aproximación”, p. 173; Balmaceda, G., Peller, G. F., “Análisis dogmático del concepto de 'perjuicio’ en el delito de estafa (especial referencia al concepto de 'perjuicio en forma de peligro')”, en Revista de Estudios de la Justicia, $\mathrm{N}^{\circ}$ 7, 2006, p. 193 y ss.

${ }^{106} \mathrm{Al}$ respecto, sobre el conjunto de la discusión, Lackner, $L K \S 263$ marg. 315 y s.; Tiedemann, $L K$ $\S 263$ marg. 236 y s., 272. En España Cerezo Mir, "La estafa procesal”, pp. 194, 197. En Chile Grisolía, "La estafa procesal", p. 421 exige ejecutoria.

${ }^{107}$ Cerezo Mir, "La estafa procesal”, p. 194, concede que en algunos casos excepcionales la consumación del delito requerirá la ejecución de la resolución. 
Cramer, P., Perron, W., “\$ 263”, en Schönke / Schröder. Strafgesetzbuch. Kommentar, 27. Aufl., Beck, München, 2006.

Coloma, R., "Vamos a contar mentiras, tralará..., o de límites a los dichos de los abogados", Revista de Derecho, Universidad Austral de Chile, Vol. XIX N 2, 2006, p. 27 y ss.

Cueto, G., El delito de apropiación indebida. Administración desleal, Ediciones Jurídicas de Santiago, Santiago, 2005.

De Francesco, G., “Art. 640”, en Crespi, A., Stella, F., Zuccalà, G. (editores), Commentario breve al Codice penale, CEDAM, Padova, 1992.

Dolcini, E.; Marinucci, G., Codice penale commentato. Parte speciale, $2^{\mathrm{a}}$ edizione, IPSOA, Assago (Milano), 2006.

Dreher, E., "Das Strafrecht hat seine eigene Methode", en GA, 1969, p. 56 y ss.

Espinosa, R., Manual de procedimiento civil. El juicio ejecutivo, $11^{a}$ edición, Editorial Jurídica de Chile, Santiago, 2003.

Etcheberry, A., El derecho penal en la jurisprudencia, $2^{\mathrm{a}}$ edición, Editorial Jurídica de Chile, Santiago, 1987.

Etcheberry, A., Derecho penal, $3^{a}$ edición, Editorial Jurídica de Chile, Santiago, 1998.

Fanelli, A., La truffa, Giuffrè, Milano, 1998.

Ferrer Sama, A., "Estafa procesal", en Anuario de Derecho Penal y Ciencias Penales, 1966, p. 5 y ss.

Fiandaca, G., Musco, E., Diritto penale. Parte speciale, Vol. II, T. II, $3^{\text {a }}$ edizione, Zanichelli, Bologna, 2002.

Garrido, M., Derecho penal, Editorial Jurídica de Chile, T. IV, Santiago, 2000.

Giehring, H., "Prozeßbetrug im Versäumnis- und Mahnverfahren - zugleich ein Beitrag zur Auslegung des Irrtumsbegriffs in $\S 263$ StGB", en $G A, 1973$, p. 1 y ss.

Grisolía, F., "La estafa procesal en el derecho penal chileno", en Revista Chilena de Derecho, Vol. 24, 1997, p. 417 y ss.

HefendeHL, R., Vermögensgefährdung und Exspektanzen, Duncker \& Humblot, Berlin, 1995.

Hefendehl, R., "§ 263”, en Münchener Kommentar zum Strafgesetzbuch (MüKo), Bd. 4, Beck, München, 2006.

Hernández, H., "Aproximación a la problemática de la estafa", en AA. VV., Problemas actuales de derecho penal, Universidad Católica de Temuco, Temuco, 2003.

Hernández, H., "Normativización del engaño y nivel de protección de la víctima en la estafa: lo que dice y no dice la dogmática", en Revista Chilena de Derecho, Vol. 37, 2010.

Herzberg, R., "Betrug und Diebstahl durch listige Sachverschaffung", en ZStW, 89, 1977, p. 367 y ss.

Hoyer, A., "§ 263”, en Systematischer Kommentar zum Strafgesetzbuch (SK), 6. Aufl., Luchterhand, Köln, 2003.

Hunter, I., "No hay buena fe sin interés: la buena fe procesal y los deberes de veracidad, completitud y colaboración”, en Revista de Derecho, Universidad Austral de Chile, Vol. XXI $\mathrm{N}^{\circ} 2,2008$, p. 151 y ss.

JäNICKE, H., Gerichtliche Entscheidungen al Vermögensverfügung im Sinne des Betrugstatbestandes, Duncker \& Humblot, Berlin, 2001.

Jаковs, G., "Rechtsentzug als Vermögensdelikt", en Sieber, U. et al. (Hrsg.), Strafrecht und Wirtschaftsstrafrecht. Festschrift für Klaus Tiedemann, Heymanns, Köln etc., 2008.

Joecks, W., Zur Vermögensverfügung beim Betrug, Dr. Peter Deubner, Köln, 1982.

KINDHÄUSER, U., "Täuschung und Wahrheitsanspruch beim Betrug”, en ZStW, 103, 1991, p. 398 y ss. 
Kindhäuser, U., Strafgsetzbuch. Lebr- und Praxiskommentar, 1. Aufl., Nomos, Baden-Baden, 2002.

Kindhäuser, U., “\$ 263”, en Nomos-Kommentar zum Strafgesetbuch (NK), 2. Aufl., Nomos, Baden-Baden, 2005.

Krey, V., Hellmann, U., Strafrecht BT 2, 13. Aufl., Kohlhammer, Stuttgart, 2002.

KüPER, W., Strafrecht BT, 6. Aufl., C.F. Müller, Heidelberg, 2005.

Labatut, G., Derecho penal, T. II, 7ª edición, Editorial Jurídica de Chile, Santiago, 1983.

LACKNER, K., “\$ 263”, en Leipziger Kommentar zum Strafgestzbuch (LK), 10. Aufl., De Gruyter, Berlin-New York, 1979.

Lucarelli, U., La truffa, CEDAM, Padova, 2002.

Maggini, A., La truffa, CEDAM, Padova, 1988.

Mitsch, W., Strafrecht BT 2, 2. Aufl., Springer, Berlin etc., 2003.

OfFERmann-Burckart, S., Vermögensverfügungen Dritter im Betrugstatbestand, Duncker \& Humblot, Berlin, 1994.

Orellana, F., PÉrez Ragone, Á., "Radiografía de la rebeldía en el proceso civil: tópicos hacia una adecuada regulación en la nueva justicia civil”, en Ius et Praxis, Año 13 N $^{\circ} 2,2007$, p. 13 y ss.

Oтто, H., "Zur Abgrenzung von Diebstahl, Betrug und Erpressung bei der deliktischen Verschaffung fremder Sachen”, en ZStW, 79, 1967, p. 59 y ss.

Pastor Muñoz, N., La determinación del engaño típico en el delito de estafa, Marcial Pons, MadridBarcelona, 2004.

Pawlik, M., Das unerlaubte Verbalten beim Betrug, Heymanns, Köln etc., 1999.

Pedrazzi, C., Inganno ed errore nei delitti contro il patrimonio, Giuffrè, Milano, 1955.

Peñailillo, D., La prueba en materia sustantiva civil. Parte general, Editorial Jurídica de Chile, Santiago, 1989.

Peñailillo, D., Los bienes. La propiedad y otros derechos reales, Editorial Jurídica de Chile, Santiago, 2006.

PÉrez Ragone, Á., "En torno al procedimiento monitorio desde el derecho procesal comparado europeo: caracterización, elementos esenciales y accidentes”, en Revista de Derecho, Universidad Austral de Chile, Vol. XIX N ${ }^{\circ}$ 1, 2006, p. 205 y ss.

Piña, J. I., Fraude de seguros, Universidad de los Andes, Santiago, 2005.

Politoff, S., Matus, J. P., Ramírez, M. C., Lecciones de derecho penal chileno. Parte especial, $2^{\mathrm{a}}$ edición, Editorial Jurídica de Chile, Santiago, 2005.

Rengier, R., Strafrecht BT 1, 8. Aufl., Beck, München, 2006.

Romero, G., Delito de estafa, $2^{\text {a }}$ edición, Hammurabi, Buenos Aires, 1998.

Romero, A., "El principio de la buena fe procesal y su desarrollo en la jurisprudencia, a la luz de la doctrina de los actos propios", en Revista Chilena de Derecho, Vol. 30, 2003, p. 167 y ss.

Roxin, C., Strafrecht AT II, Beck, München, 2003.

Samson, E., “\$ 263”, en Systematischer Kommentar zum Strafgesetzbuch (SK), 20. Lieferung, Luchterhand, Frankfurt a.M., 1986.

SCHLACK, A., "El concepto de patrimonio y su contenido en el delito de estafa", en Revista Chilena de Derecho, Vol. 35, 2008, p. 261 y ss.

Schünemann, B., "Methodenprobleme bei der Abgrenzung von Betrug und Diebstahl im mittelbarer Täterschaft”, en GA, 1969, p. 46 y ss.

SEIER, J., "Prozeßbetrug durch Rechts- und ungenügende Tatsachenbehauptungen”, en $Z S t W$, 102,1990, p. 563 y ss.

TiedemanN, K., “\$ 263”, en Leipziger Kommentar zum Strafgesetzbuch (LK), 11. Aufl., De Gruyter, Berlin-New York, 1999. 
TORío López, Á., “Acción y resultado típico en la estafa procesal”, en AA. VV., Estudios penales. Libro Homenaje al Prof. J. Antón Oneca, Ediciones Universidad de Salamanca, Salamanca, 1982.

Valle Muñiz, J. M., El delito de estafa, Bosch, Barcelona, 1987.

Walter, T., Betrugsstrafrecht in Frankreich und Deutschland, C.F. Müller, Heidelberg, 1999.

Wessels, J., Hillenkamp, T., Strafrecht BT 2, 29. Aufl., C.F. Müller, Heidelberg, 2006.

Yubero, J., El engaño en el delito de estafa, ConoSur, Santiago, 1993. 
